\title{
Un debate necesario sobre la composición del campo revisteril. Hacia una cartografía de las revistas político- culturales chilenas en el periodo 1960-1973
}

\author{
A Necessary Debate on the Composition of the Magazine Field. \\ Towards a Cartography of Chilean Political-Cultural Magazines in \\ the Period 1960-1973
}

\begin{abstract}
Resumen
En este artículo se explora la conformación del campo revisteril chileno existente entre las décadas del 60 hasta el Golpe de Estado de 1973, comprendiendo el periodo como una época signada profundamente por la relación entre la política y la cultura. De este modo, buscamos cartografiar y analizar la conformación y proliferación del campo revisteril chileno, cruzado por una madurez de los sistemas institucionales culturales y universitarios del país, así como también por la proliferación de diversos espacios y grupos independientes que actuaron como productores de revistas, labor que nos empuja a discutir una taxonomía adecuada al caso chileno con sus particularidades.
\end{abstract}

Palabras claves: Campo Revisteril, Cartografía, Intelectuales, Universidades, Grupos Culturales.

\begin{abstract}
This paper explores the conformation of the Chilean magazine field that existed between the 1960s and the 1973 coup, understanding the period as a time deeply signed by the relationship between politics and culture. In this way, we seek to map and analyze the conformation and proliferation of the Chilean magazine field, crossed by a maturity of the country's cultural and university institutional systems, as well as by the proliferation of various independent spaces and groups that acted as magazine producers, a task that prompts us to discuss a taxonomy appropriate to the Chilean case with its particularities.
\end{abstract}

Keywords: Magazine Field, Mapping, Intellectuals, Universities, Cultural Groups. 


\section{Introducción}

A partir de los aportes de diversos autores (Sarlo, 1992; Dosse, 2007, Pita, 2015; Pita y Grillo, 2016; Tarcus, 2020, entre otros), las revistas han logrado posicionarse como un importante objeto de estudio para la Historia de los intelectuales, sus debates, y redes. En la historiografía chilena durante los últimos años se han realizado diversos esfuerzos por estudiar la participación de los intelectuales de izquierda en relación al proceso político chileno (Zamorano, 2016a y 2016b; Briceño, 2020; Lozoya, 2021; Pedemonte, 2020; Alburquerque, 2011). Estos perfilan la existencia de una nutrida red de intelectuales operando en la arena pública, encontrando en las revistas vehículos privilegiados para exponer sus ideas e incidir en el debate de la época.

Los trabajos de César Zamorano han puesto atención al cómo diversas comunidades intelectuales han construido y puesto en marcha revistas, las que han cumplido con distintas tareas. Así algunas han tenido fines académicos en el área de la estética como Aisthesis (2016b), otras han puesto atención sobre el debate político y cultural en torno a la constitución del gobierno de la Unidad Popular y la presidencia de Salvador Allende, en contacto con los debates latinoamericanos de la época, como Cormorán (2016a) y La Quinta Rueda (2021a). A su vez, ha indagado en la producción de revistas ligadas al exilio y la producción intelectual en el contexto de dicha experiencia (2021b, 2021c).

En la citada obra de Zamorano, al igual que lo hace Laura Briceño (2020), la revista aparece como el medio por excelencia para la presentación en sociedad del debate y argumentación de ideas por parte de los intelectuales. Espacios donde asumen posturas políticas frente a temas nacionales e internacionales. En la obra de Ivette Lozoya (2021), si bien las revistas son consultadas en un universo heterogéneo de fuentes, al analizar la inserción de intelectuales del MIR en espacios de producción de conocimiento en ciencias sociales, resalta la presencia de estos en revistas como Sociedad y Desarrollo, Cuadernos de la Realidad Nacional, Seminario Chile Hoy, Punto Final, y la revista Estrategia.

Las obras de Rafael Pedemonte (2020) y Germán Alburquerque (2011), ponen ambas de manifiesto el carácter internacional de los debates y redes intelectuales conformadas y activas durante la década del sesenta y setentas, interrogadas bajo la premisa de la Guerra Fría Cultural. En ambos casos, los intelectuales conformaron espacios que condensan relaciones humanas y diplomacias culturales tendientes a generar apoyos ya sea a las órbitas estadounidenses, soviéticas, o latinoamericanistas en clave emancipatoria y tercermundista. De este modo, las revistas aparecen como ventanas de acceso a debates ideológicos que expresan posiciones políticas abiertas o soslayadas, y que son utilizadas como parte de una estrategia global dispuesta a tender puentes de apoyo frente a determinadas causas o movimientos.

Considerando lo anterior, podríamos indicar en términos generales que el estudio de las revistas chilenas del periodo 1960-1973 se ha realizado de manera fragmentada, pues se ha puesto al servicio del estudio individual de las mismas. O en el mejor de los casos, se ha analizado un grupo de revistas como parte de proyectos políticos, o vitrina de ideas de grupos específicos. Frente a esto creemos necesario dar cuenta en este artículo de una revisión de las revistas desde una óptica institucional, la que podría dar cuenta de la producción revisteril de modo más global. Por lo que espacios como las instituciones universitarias, o espacios culturales 
públicos y/o privados ocuparán roles centrales a la hora de la articulación, producción y difusión de las distintas revistas.

Durante la temporalidad propuesta (1960-1973), el contexto nacional chileno podría englobarse en lo que Mario Góngora ha denominado como periodo de planificaciones globales (1981), escenario donde el tiempo histórico nacional tendió a la transformación, y que estuvo signado profundamente por "las características que adquiere la relación entre política y cultura" (Subercaseaux, 2004, p.15). Época de gran proliferación del campo revisteril chileno, que está cruzado por una madurez de los sistemas institucionales culturales y universitarios del país, así como también por la proliferación de diversos espacios independientes que actuaron como productores de revistas. Donde no podemos obviar los procesos políticos nacionales asociados a cambios estructurales como la Reforma Agraria y la Reforma Educativa, la Nacionalización del cobre, y hacia finales de los sesenta y principios de los setenta la elección de Salvador Allende con el programa de la Unidad Popular. A su vez, en escala latinoamericana el impacto de la Revolución Cubana y su impulso hacia el compromiso político de los intelectuales marcó pauta en muchas de las discusiones de la época. Esto se refleja en un impulso transversal por integrar las redes de revistas latinoamericanas, donde canjes con revistas como Casa de las Américas se vislumbra fundamental (Ayo y Ferreira, 2021).

Cabe indicar que no hemos logrado rastrear durante la realización de este artículo, obras que remitan a una descripción de los contextos de edición y producción en los términos formulados por Annick Louis (2014). Quien propone estudiar las revistas en relación a sus contextos, siempre plurales, de publicación, edición, producción y lectura. Podríamos de todas maneras dar cuenta de algunos esfuerzos cercanos como el propuesto por Christian Anwandter (2021) quién analiza la construcción de la figura del lector popular en la experiencia de la Editora Nacional Quimantú. También podríamos indicar intentos recientes por realizar un análisis transversal de la relación entre izquierdas y prensa en la obra de Cristina Moyano y Carla Rivera (2020), sin embargo, esta última no remite directamente al universo revisteril. Fuera de la temporalidad de este estudio, podríamos constatar una investigación que ha indagado sobre contextos editoriales en dictadura, como lo es ¿Apagón Cultural? El libro bajo dictadura de Manuel Sepúlveda, Jorge Montealegre y Rafael Chavarría (2017)

Si bien este artículo no pretende el aplicar la propuesta de Louis, creemos pertinente el manejar algunas categorías conceptuales sugeridas en su obra, tal como la noción de red de revistas, la que es entendida como "un espacio productor de relaciones, constituida por una serie de elementos heterogéneos" (2014, p.50). Dicho espacio, que constituyen el conjunto de revistas de un momento determinado, otorgaría un perfil particular a la organización cultural de una época, funcionando también como una instancia de poder en tanto "la red de revistas arma y determina circuitos de publicación y de reconocimiento que a veces entran en contacto con instituciones, pero mantienen siempre cierto grado de autonomía" (pp.49-50).

Frente a dicha postura, y asumiendo la premisa de Louis de que "cada época tendría un modo específico de producir estas redes" (2014, p.51), esta investigación se interroga por la producción revisteril chilena de la década de los sesenta hasta el Golpe de Estado de 1973, comprendiendo dicha época como una de grandes transformaciones en las nociones de intelectual, artista, cultura, así como en los alcances de la política y lo político. Constatándose una confluencia de los campos político y cultural, el cual también alcanza diversas esferas académicas.

Con la finalidad de contribuir al conocimiento historiográfico en torno a la producción revisteril del periodo 1960-1973, proponemos realizar un mapeo cartográfico de sus revistas. En 
esta línea, entenderemos cartografía en consonancia con la definición entregada por José Santos Herceg en Cartografía Crítica (2015), reflexionadas en torno al quehacer de la filosofía profesional en Chile. De este modo, nuestra cartografía busca elaborar un mapa del territorio (en este caso revisteril), entendiendo que en el ejercicio de registrar existe un desfase y una pérdida. Pues en palabras de Santos, "hay, junto a este límite, una elección, pues no todo se registra, no todo cabe en un mapa: el cartógrafo escoge una perspectiva, cierto escorzo, una escala" (p.12).

Aparejada a esta cartografía se hace necesario discutir una taxonomía adecuada al caso chileno, que dé cuenta del espacio que tienen las revistas político-culturales al interior del entramado humano e institucional en el que se produjeron éstas, así como otro tipo de revistas. A partir de una reflexión crítica en torno a la taxonomía que otorga Tarcus para estudiar el ciclo histórico de las revistas latinoamericanas, y también de la caracterización de la revista políticocultural que propone (2020), este artículo busca presentar un mapeo de las revistas de la época a través de las siguientes interrogantes: ¿qué espacios conformaron los principales nodos de producción revisteril en la época? ¿qué tipos de revistas convivían y cuál fue su ciclo vital? ¿es posible identificar espacios nodales en torno a la producción de las revistas de la época? Y no menos importante, ¿qué lugar juegan las revistas político-culturales en el universo revisteril de la época?

Una mirada en torno a la producción revisteril del periodo, sus principales espacios y actores relacionados a la creación y difusión de estas, busca ser un aporte a futuras investigaciones en torno al campo de estudio de las revistas. El lector comprenderá por lo demás la incompletitud de esta propuesta cartográfica, la que derivada de las difíciles y prácticamente nulas condiciones para el trabajo de archivo relacionadas a la Pandemia por COVID- $19,{ }^{1}$ lo que ha visto imposibilitado un desarrollo y profundidad mayores. Con lo que esta presentación expone algunas pesquisas realizadas en mi tesis de magister finalizada a comienzos de 2020, las que aparecen interrogadas frente a nuevos cuestionamientos relacionados con la necesidad de comprender las particularidades del caso chileno.

Pero también, y siguiendo a Santos, la construcción de este mapeo cartográfico responde a ciertas interrogantes, y por tanto no pretende lograr la inabarcable tarea de integrar la totalidad de las revistas producidas. Sino más bien, dar cuenta de una muestra relacionada a espacios humanos e institucionales de heterogénea índole, y que en su interior conviven distintos tipos de revistas que apelaron a proyectos de diversos.

\section{Hacia una Cartografía de Revistas político-culturales chilenas 60-73}

La conformación del campo cultural, político, e intelectual chileno de la década de los 60 y de los 70, estuvo marcado por una multiplicidad de actores. Los que en gran medida comparten

\footnotetext{
${ }^{1}$ Dejando fuera de esta pesquisa, meramente por una cuestión de falta de acceso a fuentes, las revistas o emprendimientos editoriales producidas y adscritas directamente por partidos políticos que se interesaron por la cuestión cultural. Grupo en el que resaltan, por ejemplo, para el caso del Partido Comunista con las revistas Aurora (1954-1968), labor que luego continua la revista Apuntes... (1971-1973); para el caso del MIR la revista Campanha (1972-1973). U otras formas de comunicación como el periódico El Siglo del que resalta su suplemento Domingo Cultural; el semanario Chile Hoy (1972-1973), entre otros. En parte también, porque algunos de estos soportes no responden directamente al formato revista, como los dos últimos casos nombrados. También se omite la producción revisteril de tipo comercial, como Ritmo por representar a nuestro parecer, un campo revisteril involucrado en otros ámbitos, no necesariamente relativo al conocimiento o la producción cultural.
} 
una validación académica e institucional, además de los reconocimientos propios del campo artístico y/o profesional en el que se inscribieron. A través de las siguientes páginas, buscaremos identificar actores (intelectuales e institucionales) centrales en la constitución de estos artefactos culturales, y además establecer sus redes intelectuales ya sean de carácter político, académico, o también para con otras revistas.

Para realizar este cometido una primera cuestión que habría que plasmar es la presencia o impulso variado, y transversal en distintas regiones de Chile, de constituir espacios de reflexión teórica a la vez que vitrina de los espacios culturales e institucionales-académicos surgidos al alero de diversas universidades y centros culturales. Es así que en el periodo que comprende esta investigación (década del sesenta y primer tercio de los setenta), hemos podido constatar la existencia de más de cincuenta revistas de carácter cultural, literario, y académico.

Estas revistas comprenden artefactos culturales de diversa calidad e índole, abarcando desde temas académicos, a otros que van de lo puramente literario y los poemarios, a revistas de crítica literaria, crítica de cine, y también de discusión y reflexión política del campo de la cultura en la convulsionada época de transformaciones que estudiamos.

Respecto a las revistas y su tipificación, Horacio Tarcus habla de un ciclo histórico de las revistas latinoamericanas, las que, nacidas propiamente tal luego de las independencias y a través del siglo XIX, proliferaron en formas y tipos. Donde podemos ubicar "de las más patricias a las más plebeyas, de las universalistas a las nativistas, de las comerciales a las contraculturales, de las de vanguardia a las de retaguardia, trazando un campo fascinante" (2020, p.19). Convirtiéndose así a lo largo del siglo XX en "los vehículos de expresión preferidos por los más diversos colectivos que disputaron posiciones dentro del campo intelectual” (p.23).

En ese sentido, las revistas no son sólo soportes materiales de diversas expresiones, sino que también representan pequeñas comunidades que forman su campo de lectores, así como también generan redes y nexos con otros espacios y colectividades. Tarcus indica que la existencia de una revista significa también una disputa por un espacio en el campo revisteril e intelectual en el que busca inscribirse, por lo que en alguna medida la lucha por lograr un lugar central en el campo las inscribe en "genealogías legitimantes" (p.23). Esta legitimación provendría de la capacidad de alianza o puesta en red de estas revistas, para así inscribirse e impactar su área al interior del campo revisteril. Cuestión de la que se desprende, siempre siguiendo a Tarcus, la existencia de la neutralidad o la rivalidad existente a la par de dicha capacidad de alianza.

Este entramado relativo a la naturaleza dialogante de las revistas, cruzadas por su presente y constituyendo un espacio de debates y propuestas, lleva a preguntarse qué entendemos en lo específico por revista cultural para esta investigación. En esta línea, nos sumamos a la reflexión de Tarcus que sitúa la revista cultural en un marco de autonomía de los espacios producción de conocimiento, diferenciándose de la prensa diaria, así como de los semanarios u otros productos políticos, y también del campo intelectual de tipo meramente académico. De esta forma las revistas culturales serían "los voceros de grupos que se proponen postular una agenda y desplegar una política cultural mediante una intervención en el campo intelectual que adopta la forma de un juego de disputas y alianzas con otras revistas por el reconocimiento, el prestigio y la legitimidad" (Tarcus, 2020, p.34).

Es menester problematizar entonces el concepto de revista político-cultural, categoría analítica que se vislumbra muchas veces aparejada e incluso homologada a la de revista cultural. El uso de este concepto ha sido utilizado recientemente para identificar revistas ligadas a corrientes y partidos políticos (Caamaño, 2020; Crespo, 2020), cabe indicar que estos trabajos no 
problematizan su uso, integrando el adjetivo de político en un sentido estrictamente ligado a la producción de las mismas por dichos partidos o corrientes.

Por nuestra parte, en este artículo utilizaremos la categoría de revista político-cultural para dar cuenta de revistas de índole cultural que, en el planteamiento de sus ideas y debates, formulan renovaciones, cambios y propuestas programáticas más allá de lo pertinente a su campo de experticia, excediendo los límites del campo cultural. En este sentido, no es necesaria la adscripción explícita a una agrupación o partido político para entrar en este grupo (independiente de que alguno de los miembros de su comité si pertenezcan), sino más bien la necesidad de articular expresiones y agendas políticas que excedan las funciones clásicas académicoprofesionales en las que se insertan originalmente. Y que se diferencia de las revistas meramente culturales, en el sentido de que entenderemos que estas últimas en el despliegue de su agenda cultural e intervención en el campo intelectual que realizan, lo hacen en el sentido de una intervención más bien disciplinar o propia del campo cultural.

Dicha salvedad es realizada tomando en cuenta los aportes de Rolando Álvarez, quién centrándose en el periodo de la Unidad Popular y analizando la centralidad que ganó la cultura para la candidatura y desarrollo del proyecto socialista, plantea que al calor de las concepciones del hombre nuevo propias del socialismo soviético y cubano, en Chile habría surgido una vertiente en la izquierda que denomina "pragmatismo iluminado", la que se abrió paso entre las concepciones castristas y leninistas de dicho hombre nuevo. Dicha posición, argumenta, surgió más bien de la praxis de la izquierda, que de la teoría en sí misma (2014). Esta heterodoxia del componente intelectual chileno de la época, nos permite entonces ubicar el componente político de la relación político-cultural de la revista, en un margen que supera el de los partidos políticos, pero no necesariamente los abandona. Del modo que las colaboraciones entre militantes de partidos y militantes del proyecto de la Unidad Popular (pero no adscritos a partidos) serán constantes.

También es necesario tener en cuenta que, al interior de este campo revisteril chileno, y como indicamos antes, existe una gran variedad de revistas, tanto en lo que respecta a su temática, como también a su capacidad de alcanzar centralidad u hegemonía al interior del campo, expresado tanto en la calidad material e intelectual de las publicaciones, así como también de las redes que permiten vislumbrar.

Consultando posibles nociones para trabajar el entramado revisteril chileno de la época, encontramos la propuesta de taxonomía aportada por Raymond Williams en Marxismo y Literatura, y rescatada por el ya citado Horacio Tarcus para el análisis de las revistas latinoamericanas. En tal caso, podríamos organizar las revistas indagadas en: hegemónicas, contrahegemónicas, emergentes y residuales. Ahora bien, dicha conceptualización no es estática, sino que más bien Tarcus advierte la historicidad de las revistas, pues "una misma revista de larga duración puede irrumpir en determinado momento del campo como revista emergente, disputar durante cierto tiempo la hegemonía del campo a las consagradas, alcanzar luego de un lapso la condición de revista hegemónica", y luego de un tiempo, "sobrevivir finalmente a su reinado como una revista residual" (Tarcus, 2020, p.24).

Dicha taxonomía, dígase de paso, la pondremos en diálogo con una propia derivada de la adscripción institucional de las revistas. Esto pues como hipótesis podemos indicar que el ciclo vital de las revistas político-cultural chilenas tiende generalmente a un desgaste rápido, derivado de la incapacidad de financiar su producción, más que de su capacidad de generar redes de aportes intelectuales o la calidad de su contenido. Idea que, frente al desconocimiento respecto a la circulación de las revistas entre el público lector (en cuanto mercado de consumo masivo de 
estas), empuja a creer que el ciclo vital de las revistas estuvo fuertemente ligado a la capacidad de recibir fondos estatales por algún canal institucional. Pues cuando las revistas carecen de dichos aportes financieros, generalmente tienden a la discontinuidad de sus números, así como también, a una menor calidad del material, y a su rápida desaparición.

Es así que propondremos al menos tres categorías ligadas a la adscripción institucional, entre las que encontramos: a) las revistas universitarias o asociadas institucionalmente a una casa de estudios, b) las revistas de centros independientes (entendidos por centros culturales locales pequeños, grupos independientes sin afiliación institucional formal); y c) revistas ligadas a instituciones culturales formales (como museos, editoriales estatales, asociaciones de artistas, literatos, etc.).

Entenderemos por lo demás, que en la indagación sobre las revistas de la época que hemos logrado realizar, han de surgir subdivisiones. Así mientras existen revistas universitarias de corte más bien intelectual-académico, también las hay del tipo cultural o político-cultural. De la misma manera, diversos centros o grupos independientes pueden presentar desde poemarios hasta análisis de la realidad nacional. Lo mismo con las revistas de instituciones culturales formales, las que pueden reunir desde diversos tipos de estudios hasta antologías comentadas.

Cabe mencionar, tal como veníamos comentando en torno al campo revisteril chileno de la época, que la vida de las revistas suele ser de corta duración. Observaremos a través de los siguientes apartados que en este corto periodo de tiempo surgen y caen diversas publicaciones, algunas realizadas con mayores recursos que otras, donde ciertas revistas a pesar de su densidad intelectual no logran sobrevivir a los flujos y vaivenes económicos, sociales y políticos de la época. Mientras que otros, principalmente asociados a vertientes intelectual-académicas ligadas a centros universitarios, tuvieron (y en algunos casos, aún tienen) mayores posibilidades de sobrevivir las profundas transformaciones de la segunda mitad del siglo XX chileno.

A continuación, haremos un repaso por el campo revisteril de la época que hemos pesquisado hasta el momento. Para realizar esta tarea, categorizaremos el universo revisteril a través de su adscripción institucional, dando cuenta de sus conformantes y ciclo vital, ${ }^{2}$ así como también haciendo eco de algunos debates y redes. Posteriormente, y una vez realizado un mapeo general, propondremos una lectura del campo revisteril dando cuenta de algunas especificidades de las revistas político-culturales en relación con otro tipo de revistas de la época, centrándonos en lo que respecta a su ciclo vital. Haciendo finalmente un comentario por los intelectuales de la época, sus trayectorias en las diferentes revistas, y sus nexos con las principales instituciones del país.

Cabe advertir que se pondrá mayor interés, y por tanto se indagará con mayor profundidad, en lo que respecta al análisis de revistas culturales y político-culturales. Sin embargo, se hace menester también integrar (aunque sea de forma menos acuciosa) la producción académica universitaria, pues en su comparación en lo que respecta a sus adscripciones institucionales y ciclos vitales, podríamos encontrar algunas luces respecto a la composición del campo revisteril de la época y el lugar que ocuparon las revistas culturales en este.

\footnotetext{
${ }^{2}$ Esta labor se referenciará a pie de página, o en el cuerpo del texto cuando se estime conveniente. La información respecto a la conformación de los comités editoriales de las revistas no está completa en todos los casos, por lo que la fragmentación de la información es un dato a considerar por el lector.
} 


\section{Mauricio Tapia Segovia}

\section{Revistas universitarias o asociadas institucionalmente a una casa de estudios}

Un grupo importante de revistas de la época en estudio fueron auspiciadas o nacidas al alero de diversas instituciones de carácter académico y universitario, jugando la Universidad y los Centros Académicos un punto de reunión, influencia y propagación de las diversas redes culturales y políticas del país, representando espacios nodales importantes para tener en cuenta a la hora de reconstruir cualquier red intelectual en torno al campo político-cultural chileno. De hecho, muchos de los intelectuales que editan, dirigen, y participan de las revistas consultadas están ligados directamente al mundo universitario, tanto como estudiantes o académicos, jugando así este espacio un claro rol articulador del campo de las revistas culturales.

En distintas latitudes de Chile surgen revistas de diversa índole, las que comparten algunas ventajas relativas en comparación con, por ejemplo, sus pares independientes. Estas ventajas se relacionan con mayores fuentes de financiamiento, respaldo institucional, y difusión. Traduciéndose generalmente en revistas de mayor alcance, con aportes teóricos más sólidos, y también con redes de canje más diversas.

Dentro de esta categoría podemos ubicar a revistas como Áncora (1965-1972), que al alero de la Universidad de Chile y su sede norte (Antofagasta) logra editar una revista con la misión de valorizar los parajes y aportes culturales surgidos en esta zona del país. Su adscripción institucional es clara, integrando como subtítulo en sus cinco números la denominación de Revista cultural universitaria, e indicando en su nota inicial del primer número que la revista surge de un esfuerzo del Departamento de Extensión Cultural (a cargo de Mario Bahamonde, director de la revista) del Centro Universitario Regional Zona Norte de la Universidad de Chile, dirigido por Hugo Acuña Matus, bajo la rectoría de Eugenio González Rojas.

También en el norte del país, pero esta vez situados desde Arica y adscritos a la sede regional de la Universidad de Chile de esa ciudad, podemos ubicar a Tebaida ${ }^{3}$ (1968-1972). Al igual que para el caso de Áncora, en esta revista circulan principalmente estudiantes, académicos, y artistas regionales, aunque con la importante distinción de que la dirección de la revista estaba a cargo del Grupo Tebaida, ${ }^{4}$ donde resalta la figura de su directora Alicia Galaz Vivar catedrática de Lengua y literatura Medieval de la casa de estudios, y de las pocas mujeres del periodo (junto a María Flora Yáñez directora de la revista La Honda, y Marina Latorre de Portal) en encabezar una iniciativa de este tipo.

Si bien como indicamos, la revista presenta principalmente a figuras locales, su labor consignada a presentar obras literarias de diverso tipo da como resultado la inclusión de figuras de otras latitudes como a Jaime Quezada (director del Grupo Arúspice de Concepción, y la revista del mismo nombre), a Omar Lara (director y fundador del Grupo Trilce de Valdivia, y su revista homónima). O diferentes catedráticos y artistas arequipeños para el caso específico del número doble (3-4), el que además tiene en su portada un extracto del discurso triunfal de Salvador Allende el 5 de noviembre de 1970 en el Estadio Nacional.

El triunfo de la Unidad Popular otorga un nuevo cariz a la revista, en el sentido de que si bien lo principal continúa siendo la difusión literaria, desde el número cinco (primer cuatrimestre

\footnotetext{
${ }^{3}$ Directora: Alicia Galaz, director de Ediciones Tebaida: Miguel Morales Fuentes, Portadas Xilografías de Guillermo Deisler, Grabados de Luis Moreno Pozo, Imprenta Iglesias-Arica. Patrocinan Federación de Estudiantes, Universidad de Chile-Arica, Departamento de Cultura: Ariel Santibáñez.

${ }^{4}$ También resaltan figuras como la de Guillermo Deisler, Oliver Welden, Andrés Sabella, Luis Moreno Pozo, entre otros.
} 
de 1971), comienzan a figurar de manera más evidente algunos comentarios relativos a la cuestión política. Así resalta el texto Poesía y Justicia del poeta, narrador y periodista antofagastino Andrés Sabella, que narra un acto político convocado por la Universidades de Chile y Técnica del Estado en el norte el día 9 de julio de 1971, donde se llevó a cabo un "juicio público al capitalismo" en la calle principal de la ciudad. Acto que Sabella (quién además es integrante del grupo Tebaida) aplaude alegremente, indicando que "este juicio finaliza en esperanza revolucionaria. Nuestra misión no espera para avanzar "hacia la luz, hacia la conciencia"." (Tebaida $\mathrm{n}^{\circ} 5,1971$ ). Línea editorial que continuará en el número 6, con un texto del autor puertorriqueño José Manuel Torres Santiago titulado Revolución y Poesía y que aboga por ligar la historia de la literatura con la lucha de clases, y que concluye en el número siguiente $\left(n^{\circ} 7\right.$, 1972), edición que incluye alusiones a figuras de la tradición revolucionaria latinoamericana como Camilo Torres o Juan Carlos Mariátegui.

En la zona sur del país podemos ubicar revistas como Arúspice (1965-1968) ${ }^{5}$ la que bajo el auspicio del Departamento de Asuntos Estudiantiles de la Universidad de Concepción se presenta como un poemario de difusión de artistas chilenos y latinoamericanos, encabezado por el Grupo Arúspice conformado principalmente por estudiantes de la universidad. Entre estos podemos ubicar a Jaime Quezada, Silverio Muñoz, Sonia Quintana, Jorge Narváez, José Luis Montero y Edgardo Jiménez, a los que se suman figuras como Floridor Pérez (profesor rural de castellano, escritor y director de la revista Carta de Poesía 1966-1967) y el poeta Gonzalo Millán.

Al igual que sus contemporáneas, esta revista buscó rápidamente generar lazos con otros grupos editoriales, tanto nacionales como internacionales, resaltando desde el número doble (n³4, febrero de 1967), canjes con la importante revista cubana Casa de las Américas, así como introducción de textos de Julio Cortázar e intelectuales cubanos. Así en su última entrega ( ${ }^{\circ} 7-8$ de 1968), aparece como excepción a la revista, un texto de carácter político escrito por el cubano José Lezama Lima titulado La responsabilidad del intelectual ante los problemas del mundo desarrollado, abogando por el reconocimiento de la revolución como motor de la producción artística y cultural. Cabe indicar que la revista acaba su ciclo en relación con la finalización de los estudios universitarios en Concepción de los integrantes del Grupo Arúspice, trasladándose varios de ellos a otras latitudes.

Producida en Valdivia bajo la tutela de la Universidad Austral, y la dirección del poeta, editor y traductor Omar Lara, se publica la revista Trilce ${ }^{6}$ (1964-1973). Esta publicación, que fue nombrada en honor del grupo Trilce, buscaba dar cuenta de la producción poética universitaria, sumándose a sus filas figuras como el joven profesor de estética Federico Schopf, o desde Santiago el poeta Waldo Rojas, y donde participaron importantes figuras como el intelectual Luis Oyarzún. Su labor de difusión literaria fue sistemática, combinando la poesía nacional de Tellier y Gonzalo Rojas, con aportes de autores como Bertolt Brecht y Apollinaire.

En la ciudad de Temuco se publicó Stylo $^{7}$ (1965-1980) producida por las Escuelas Universitarias de La Frontera, actual Universidad Católica de Temuco. Cabe indicar respecto a esta publicación, que es una de las pocas revistas de tipo cultural que logra sortear con vida la experiencia del Golpe de Estado y los primeros años de la Dictadura. A modo de hipótesis,

${ }^{5}$ Con un total de 8 números, sus directores eran los estudiantes Silverio Muñoz (Esc. de Educación) y Jaime Quezada (Esc. de Derecho).

${ }^{6}$ Grupo Trilce: Omar Lara (fundador y director), Carlos Cortínez, Walter Hoefler, Federico Schopf, Eduardo Hunter, Juan Epple, Enrique Valdés, Luis Zaror, Luis Oyarzún, Floridor Pérez, Waldo Rojas (diagramación).

${ }^{7}$ Director: Jaime Arellano. La revista no se publicó entre 1978 y 1979. 
podríamos plantear que el hecho de que su ciclo vital no se vio afectado, responde principalmente al carácter academicista presentado en los artículos que contiene la revista, una línea que (a diferencia de las otras revistas de la época) no se ve impactada profundamente hacia finales de los sesenta con el impulso que empujó a diversas revistas a incluir autores "revolucionarios", o textos que abogaban por la relación entre política y cultura.

De vida efímera, pero marcando un precedente, surgió en Concepción la revista Nueva Atenea $(1970)^{8}$ a cargo de Enrique Lihn. Revista que buscaba actualizar a los nuevos tiempos (Unidad Popular) a la ya clásica revista Atenea, producida en la Universidad de Concepción desde 1924, y aportando diversos análisis de la realidad nacional. De este modo, y signado bajo los contextos políticos de la puesta en marcha de la Reforma Universitaria y la Victoria de Salvador Allende y el Gobierno de la Unidad Popular, la ya clásica Atenea cambia su nombre temporalmente en sus números 423 y 424, indicando en su editorial que "la tarea de Nueva Atenea se confunde, en las instancias de la Reforma, con la voluntad de ahondar y fortalecer una conciencia latinoamericana que exprese a través de esta revista la unidad básica de los países del continente en cuanto a sus problemas y soluciones" (Nueva Atenea n $423, \mathrm{p} .1$ ).

Un elemento distintivo en la revisión de estas revistas de regiones es que, a diferencia quizás de Nueva Atenea, las publicaciones que hemos referenciado tienen una línea editorial más bien ligada a una tarea de difusión del campo cultural regional, nacional e internacional, con algunos atisbos -más o menos marcados-, de crítica, pero donde lo central es la difusión de la literatura y las artes. Mientras que Nueva Atenea bajo la dirección de Enrique Lihn tendrá una línea marcadamente política, signada por temas como Universidad y sociedad, el arte el cubano, la dependencia económica del tercer mundo, y la política cultural del gobierno de Salvador Allende. De este modo se propone en sus editoriales que "la lucha universitaria se inscriba en la que ha emprendido el nuevo Gobierno, adquiriendo así la Reforma universitaria, en un contexto más amplio, todas sus cualidades latentes", puesto que "es la primera vez que un gobierno chileno se dispone a abordar frontalmente el problema de la cultura, y este solo propósito sanciona para nosotros el carácter creador de la misma con respecto a la vida social" (Nueva Atenea, n424, p.1). Entre las figuras que resaltan en las páginas de esta efímera revista, encontramos comentarios críticos de personajes como Federico Schopf, Armand Mattelart, y el mismo Enrique Lihn, intelectuales que participan como es posible observar a través de este artículo, de otras revistas importantes para la época de estudio.

Acercándonos a la zona central del país, principalmente el enclave Santiago-Valparaíso, nos encontramos con diversas revistas producidas principalmente al alero de la Universidad de Chile y la Universidad Católica. Donde muchas de estas asumen un carácter de tipo académico, ligados a diferentes departamentos y escuelas. Podremos observar respecto a su ciclo vital, que al igual que lo ocurrido con la revista Stylo, estas logran sortear (debido a su contenido relativo a conocimiento científico o disciplinar) el impacto del Golpe de Estado y la desarticulación político-intelectual del periodo.

En este grupo podemos nombrar a la Revista Chilena de Literatura (1970-actualidad) ${ }^{9}$ editada por el Departamento de Español de la Universidad de Chile en Santiago; también resaltan

${ }^{8}$ Director: Enrique Lihn; Comisión Consultiva: Edgardo Enríquez Frödden (Rector U. Concepción), Galo Gómez (Vicerrector), Gonzalo Rojas (director del Consejo de Difusión Universitaria), Diagramación: Tito Valenzuela, Fotografías: Armando Cardoso.

${ }^{9}$ Coordinador: Hernán Loyola; Comité Editor: Hernán Loyola, Carlos Santander, Antonio Skármeta; secretaria: Marta Espinoza; Bibliotecaria: María Antonieta Parraguez; Diagramador: Mariano Rawicz- 
el Boletín Instituto de Filología ${ }^{10}$ (1947-actualidad) de la Universidad de Chile; el Boletín de la Universidad de Chile C11 $^{\text {(1959-1971); Estudios Internacionales }}{ }^{12}$ (1967- actualidad) del Instituto de Estudios Internacionales de la Universidad de Chile; y Revista del Pacífico ${ }^{13}$ (1964-1968) editada por el Instituto Pedagógico de la Universidad de Chile en Valparaíso.

Mientras que por el lado de la Universidad Católica surgen revistas como Taller de Letras (1971-actualidad) ${ }^{14}$ bajo el alero del Instituto de Letras de la Pontificia Universidad Católica de Chile; Aisthesis ${ }^{15}$ (1966-actualidad) del Instituto de Estética de la Universidad Católica de Chile $^{16}$; y también Finis Terrae ${ }^{17}$ (1954-1967 / 1993-2005) publicación del Departamento de Extensión de la misma universidad. También encontramos algunas como la Revista Impulso (1960-1979) de 8 números, publicación del Centro de Alumnos y de la Fundación de Ingenieros de la Escuela de la PUC. Apuntes (1960-2019) publicación ligada al Teatro de Ensayo de la Universidad Católica, Teología y Vida (1969- actualidad) y Anales de la Facultad de Teología (1960-actualidad), ligadas a dicha facultad de la UC.

También podemos referenciar en este grupo la Revista de Biología Pesquera (1961-2008), editada por la Estación de Biología Marina de Valparaíso; la Revista Historia (1961-actualidad), ligada al Departamento de Historia; los Cuadernos de Economía (1963-2010), de la Facultad de Ciencias Económicas y Sociales; Anales de la Facultad de Filosofía y Ciencias de la Educación (1965-1969); la Revista Signos (1967-2008) ligada al Departamento de Castellano de la Universidad Católica en Valparaíso; o Apuntes de Ingeniería (1972-1997) de la Escuela de Ingeniería. Además, podríamos incluir en este grupo de revistas de tipo académico a la Revista de Educación Diferenciada (1972-1973), con la salvedad de que esta se produjo bajo la Tutela de la Universidad Católica del Maule.

Cabe mencionar también la experiencia de las revistas de la Universidad Técnica del Estado, la que durante la década de los sesenta contó con diversas revistas editadas por círculos estudiantiles $^{18}$. Impulso que desde 1969, con la llegada de Enrique Kirberg a la rectoría de la UTE y la creación del Departamento de Extensión y Comunicación, se potenció con la creación de diversas publicaciones institucionales. Entre ellas se pueden destacar el Boletín Académico y Cuadernos de la Reforma publicados por Editorial UTE, la revista de Contribuciones Científicas y Tecnológicas (1970-2005) dirigida por Tomás Ireland, Unitécnica realizada por la Oficina de Relaciones Públicas, Presencia UTE (1972-1973) por el Departamento de Comunicaciones, la Revista de la Universidad Técnica del Estado (1969-1973), el Boletín del Instituto Pedagógico

${ }^{10}$ Director: Rodolfo Oroz.

${ }^{11}$ Director Interino: Jorge Teillier.

${ }^{12}$ Director: Ricardo Gott.

${ }^{13}$ Secretario de Redacción: Nelson Osorio y Luis Iñigo Madrigal.

${ }^{14}$ Director: Jorge A. Román-Lagunas ( $\left.n^{\circ} 1-2\right)$, Cedomil Goic ( $\left.n^{\circ} 3\right)$; directora Adjunta: Adriana Valdés ( ${ }^{\circ} 1$ y 3 ), secretario de redacción: Ignacio Rodríguez $\left(n^{\circ} 1\right)$, Ester Lagos (n³); Coordinadora: Carmen Foxley, Consejo de Redacción: Alfonso M. Escudero O.S.A., Ernesto Sábato, Carlos Droguett, Paulius Stelingis, Hugo Montes, Luis Wainerman, Fidel Sepúlveda, Cecilia Beucha, Ignacio Osa, Eligio García Marquez, Janice Dewey. Diagramación: Víctor Gubbins $\left(\mathrm{n}^{\circ} 2\right)$, Eddy Carmona y Any Maskymowicz $\left(\mathrm{n}^{\circ} 3\right)$.

${ }^{15}$ Director Raimundo Kupareo. La revista luego tuvo otra época: 1993 hasta 2005.

${ }^{16}$ Ver César Zamorano Díaz: "Revista Aisthesis y el desarrollo de la estética en Chile”, Aisthesis no.60 Santiago dic. 2016.

${ }^{17}$ Director: Jaime Martínez Williams, secretario de Redacción: Carlos Ruiz Tagle.

${ }^{18}$ Entre estas revistas podemos nombrar Vértice del Centro de Alumnos de Ingeniería Industrial, Brecha de la FEUTE y de adscripción al Partido Comunista, las revistas El Universitario y Decito adscritas al Partido Demócrata Cristiano, la revista Contacto de Metalurgia y Carlin de Publicidad. 
Técnico ${ }^{19}$ (1964-1970); y más acorde con nuestra investigación: Talleres de cultura, editada por la Secretaría Nacional de Extensión y Comunicación y dirigida por Mario Navarro ${ }^{2021}$.

Mientras que en otra arista, en el enclave Santiago-Valparaíso también se editaron revistas de tipo literario, cultural y político-cultural. En esta línea y bajo la tutela de la Universidad de Chile, surgen hacia finales de la década de los sesenta dos revistas culturales: Árbol de Letras (1967-1969) ${ }^{22}$ y Cormorán (1969-1970), ${ }^{23}$ editadas bajo el auspicio de la Editorial Universitaria, y domiciliadas en la ciudad de Santiago. Resalta en ambas revistas no sólo la amplia inserción en redes de canje y aportes de figuras intelectuales latinoamericanas, así como la participación en los debates de la época como la Revolución Cubana con la polémica de Heberto Padilla y las intervenciones de Julio Cortázar, sino que también la posibilidad de visualizar (hacia finales de los sesentas) la evolución en la configuración de los intelectuales en el campo revisteril y también la tendencia a la demarcación explícita del compromiso político del mundo de la cultura.

Para graficar estas redes, una pequeña revisión de las trayectorias de sus comités editoriales sería útil. Para el caso Árbol de Letras, en su dirección resalta la figura de Antonio Avaria, quién siendo poeta, ensayista e importante crítico literario, también fue profesor universitario, haciendo su carrera en la Universidad de Chile. Antonio Avaria colaboró además como columnista en revistas como Ramona (1971-1973, Juventudes Comunistas) Cormorán (Universidad de Chile) y Taller de Letras (Pontificia Universidad Católica de Chile), siendo además jefe de redacción de la Gaceta Literaria del diario La Nación, y encargado de la sección cultural de la revista Desfile (1965-1971). También participó como profesor e investigador del Centro de Estudios de la Realidad Nacional (Pontificia Universidad Católica de Chile), y animador y libretista del programa televisivo Libro Abierto, emitido por el canal de la Universidad de Chile junto a Antonio Skármeta. Por último, cabe indicar que fue miembro del consejo de redacción de revistas como Mensaje, y articulista de revistas como Ercilla, Hoy, Araucaria y Alerce.

Otra figura relevante es la del poeta Jorge Teillier, quien durante la década de los cincuenta viaja a Santiago para estudiar Historia en el Instituto Pedagógico de la Universidad de Chile, donde conoció a diversos poetas y escritores contemporáneos a su generación como Francisco Véjar, Braulio Arenas, Rolando Cárdenas, Enrique Lihn o el novelista Enrique Lafourcade. Teillier además de su trabajo como directivo de Árbol de Letras, fundó junto a Jorge Vélez en 1963 la revista de poesía Orfeo (1963-1968), la que además dirigió hasta 1965, también dirigió el Boletín de la Universidad de Chile, y colaboró con escritos para revistas como Arúspice, Carta de Poesía, Guion Literario, y Tebaida. Los nexos políticos de Jorge Teillier no son claros del todo, es una figura que se le ha ligado al Partido Comunista por cercanía, pero que no habría participado directamente del partido.

${ }^{19}$ Dirección: Sara Flores López, Redacción: Nemesio García.

${ }^{20}$ Caricaturista y diseñador gráfico de la UTE en 1967. Colabora además con revistas como Brecha, Topaze, Ultima Hora, Ramona. En 1970 asume con subdirector del Taller Gráfico UTE.

${ }^{21}$ Ver en este mismo Dossier el trabajo de Simón González.

${ }^{22}$ Director: Antonio Avaria, subdirector: Jorge Teillier, diagramación: Nelson Leiva.

Representante Legal: Eduardo Castro LeFort, propietario: Editorial Universitaria S.A. domiciliada en San Francisco 454, Santiago de Chile.

${ }^{23}$ Director: Enrique Lihn, jefe de redacción: Germán Marín, secretaria de redacción: Eugenia Neves, diagramación: Vicente Larrea, Eduardo Lihn, y Juana Robles. Representante Legal: Eduardo Castro Le-Fort. Ver Zamorano (2016a). 
Otra personalidad que es necesario referenciar para el caso es la del pintor y dibujante Nelson Leiva, quién desarrolló sus estudios y carrera académica en la Escuela de Bellas Artes, ligada también a la Universidad de Chile. Leiva se ocupó de la diagramación de la revista Árbol de Letras, y también participó de otros proyectos desempeñándose en su área gráfica en revistas como Ramona, y Paula revista femenina editada originalmente por la Editorial Lord Cochrane de propiedad del fotógrafo y empresario Roberto Edwards Eastman.

De esta manera podemos aventurarnos a decir que las redes que sustentan la revista Árbol de Letras tienen sus nexos domiciliados principalmente en la Universidad de Chile, actuando como directivos y editores figuras académicas importantes ligadas a sus institutos universitarios. Espacio de legitimidad y respaldo institucional que permitió realizar los diversos nexos nacionales e internacionales, y además creó las condiciones de distribución para que la revista alcanzara difusión y circulación.

Ahora bien, si nos centramos en el caso de Cormorán, y tomamos en cuenta la conformación de su núcleo directivo y editorial, resalta la figura del célebre escritor, crítico literario, poeta y dibujante chileno Enrique Lihn; quién tuvo un truncado paso por la Escuela de Bellas Artes de la Universidad de Chile durante la década de los cuarenta, para luego decidirse por el campo literario. Sus primeras obras de tipo poemario que fueron editadas en 1949 y 1955, mismo tiempo donde realiza la obra El Quebrantahuesos junto con Nicanor Parra, Alejandro Jodorowsky, Jorge Sanhueza, Jorge Berti, Roberto Humeres y Luis Oyarzún. Ya entrada la década de los sesenta. Lihn se presenta como un escritor reconocido, lo que le valió por ejemplo una beca UNESCO gracias a la que viaja a Europa lo que nutrió su obra, y lo llevaría a ganar en 1966 el Premio Casa de las Américas, evento que le permite vivir dos años en la Cuba revolucionaria y trabajar para Casa de las Américas, donde además escribió en el diario Granma, redactó catálogos de arte y editó una antología de Vicente Huidobro.

En términos académicos, Lihn dirigió el taller de poesía de la Universidad Católica de Chile (1970-1973) y fue profesor investigador de literatura en el Centro de Estudios Humanísticos, encabezado por Cristián Huneeus, de la Facultad de Ciencias Físicas y Matemáticas de la Universidad de Chile desde 1972. Políticamente hablando, Lihn era un abierto hombre de izquierda, lo que queda patente en su militancia en el Frente de Acción Popular apoyando las candidaturas de Allende para las elecciones presidenciales de 1958 y 1964, y posteriormente encabezaría junto a otros intelectuales el Taller de Escritores de la Unidad Popular, espacio artístico e intelectual que apoyó la victoriosa candidatura de Allende en las elecciones de 1970, y que generará un núcleo de debate en torno a la política cultural del país.

En cuanto a su participación en revistas culturales de la época, como indicamos Lihn también tendrá un paso como director por la revista Nueva Atenea de Concepción, publicación que buscó refrescar la ya clásica revista Atenea frente a la contingencia nacional, proyecto que no perduró y solo tuvo dos números; mientras a principios de los sesenta tendrá una fugaz participación como director del cuarto número de la revista Alerce de la SECH y la Universidad de Chile, y a fines de la década del cincuenta, fue director del Boletín de la Revista de Arte (1959) de la Facultad de Bellas Artes de la misma casa de estudio. El escritor en su calidad de elemento vivo y central del campo literario y cultural chile, es referenciado en diversas revistas de la época en su calidad de literato y poeta; de esta manera se pueden datar colaboraciones con publicaciones como la Revista Chilena de Literatura (Universidad de Chile, Santiago), Taller de Letras (PUC), Tebaida (Universidad de Chile, Arica), y Trilce (Universidad Austral).

Otro personaje importante que reseñar de Cormorán es el escritor chileno Germán Marín, quien cursó estudios de Ciencias de la Comunicación en la Universidad de Buenos Aires, y que al 
volver a Chile durante la década de los sesenta se vincula al Partido Comunista de Chile. A mediados de los sesenta viaja a trabajar a China junto a su familia, y al regresar colabora con diversas iniciativas editoriales.

No menos importante fue la colaboración en gráficas de Vicente Larrea Mangiola, quién se formó a principios de los sesenta en la Escuela de Artes Aplicadas de la Universidad de Chile, trabajando tempranamente en 1963 en su calidad de estudiante en el Departamento de Extensión Cultural de la Universidad de Chile. Larrea junto a su hermano fundarán su primera oficina gráfica $^{24}$ en el centro de Santiago en 1967, la que gracias a los contactos realizados por Carlos Quezada (integrante de Quilapayún) tendrá un importante acercamiento a los exponentes de la Nueva Canción Chilena, participando así en la carátula del primer disco de Víctor Jara con Quilapayún, lo que le valió un importante vínculo con este movimiento musical, del cual se hizo cargo de su imagen.

De esta manera, la oficina de los Larrea realizó diversos trabajos, entre los que destacan los logotipos asociados a la imagen del sello DICAP, realizando más de 100 carátulas y 300 carteles. Este acercamiento al sello discográfico en cuestión podría revelar también nexos políticos hacia la izquierda, y principalmente el PCCh, pues el DICAP fue fundado en 1967 por las Juventudes del Partido Comunista, colectividad emparentada directamente con Antonio Avaria, y que al menos comparte simpatías políticas con Lihn, al apoyar ambos la misma candidatura y proyecto de sociedad para Chile: la de la Unidad Popular.

Continuando con la revisión de las revistas asociadas a canales institucionales universitarios, no podemos dejar fuera de esta cartografía a los Cuadernos de la Realidad Nacional (1969-1973), ${ }^{25}$ editada por el Centro de Estudios de la Realidad Nacional de la Universidad Católica, publicación de análisis teórico de la sociedad donde es posible rastrear debates en torno a la política cultural chilena del gobierno de Salvador Allende, y temas generales de índole político con la participación de importantes intelectuales de izquierda.

Una última revista que hemos podido rastrear en esta categoría, editada hacia el final de la temporalidad es Primer Plano: revista de cine (1972-1973), ${ }^{26}$ editada por el Comité de Extensión cinematográfica y la tutela de la Vicerrectoría de Comunicaciones de la Universidad Católica de Valparaíso. Primer Plano se plantea como una revista especializada en cine, y si bien plantea que su intención radica en amplificar "una misma pasión por el cine y una misma vocación universitaria. Más allá de cualquier posición estética personal, orientación ideológica 0 compromiso político" ( $\mathrm{n}^{\circ} 1, \mathrm{p} .3$ ), presenta debates contingentes a su contexto de producción, dígase el periodo más álgido de la Unidad Popular, signado por la contraofensiva política y económica en contra del gobierno de Salvador Allende.

De este modo las temáticas que exhibe tienen relación con la relación entre el campo del cine y la política, asumiendo los debates de la época, planteando además análisis críticos a la política cultural de la Unidad Popular en materia de cine. En esa línea, mientras reconocen valor en iniciativas como los Talleres Cinematográficos de Chile Films, los cuales "sin exigir matricula

${ }^{24}$ Esta oficina trabajó con un equipo conformado por Luis Albornoz, Ximena del Campo, Hernán Venegas, Mario Román y Maricruz Larrea, entre otros colaboradores

${ }^{25}$ Comité editorial: Jacques Chonchol, Gonzalo Arroyo, Gustavo Beyhaut, Ricardo French-Davis, Gabriel Gyarmati, Franz Hinkelhammert, Armand Mattelart, José Ricardo Morales, Igor Saavedra, Claudio Véliz, Raúl Veloso. Ver Zamorano (2021).

${ }^{26}$ Director: Héctor Soto Garandillas, diagramación: Allan Browne E., Alejandro Rodríguez M., consejo editorial: Hvalimir Balic Mimica, Luisa Ferrari de Aguayo, Aldo Francia B., Orlando Walter Muñoz, Sergio Salinas R., Agustín Squella Narducci, Fotografía: Juan Hernández T. 
ni otro requisito [...] han recibido un heterogéneo grupo de estudiosos, que va desde jóvenes, estudiantes, intelectuales, artistas, obreros, empleados, hasta profesionales de distintas especialidades." (Primer Plano $\mathrm{n}^{\circ} 1,1972$, p.26). Por otra parte, son fuertes críticos de la evolución que sufrió el documento del Grupo de Cineastas por la Unidad Popular, planteando además una clara ausencia de crítica en el cine chileno de la época, o al menos la ausencia de una crítica cinematográfica especializada y profunda. Labor que por lo demás buscan realizar a través de las páginas de la revista.

En otra arista, es posible rastrear a través de sus números, los contextos materiales de la producción y difusión cinematográfica de la época, cruzados por la cuestión de la amenaza de abandonar el país por productoras extranjeras, y por consiguiente el cese de la circulación del grueso de películas americanas y europeas. Es así que plantean, en contra de voces disímiles, que "considerar que el país puede prescindir de ese material en razón de que comenzará a difundirse la producción de otras cinematografías, es condenar eternamente a los chilenos a tener un panorama incompleto y parcial - como lo han tenido hasta hoy- del cine contemporáneo" (Primer Plano $n^{\circ} 2,1972$, p.3). Esta labor critica que llevó a cabo la revista a través de 5 números, se vio interrumpida por el Golpe de Estado, quedando su número 6 sin publicarse hasta el año 2018 cuando fue rescatada por el Departamento de Extensión Cultural de la Universidad de Chile en conjunto con la Cineteca Nacional como una pieza patrimonial relativa a la historia del cine chileno. 
Un debate necesario sobre la composición del campo revisteril. Hacia una cartografía de las revistas políticoculturales chilenas en el periodo 1960-1973

Mauricio Tapia Segovia

\begin{tabular}{|c|c|c|c|}
\hline AÑO & FILIACIÓN & REVISTAS & \\
\hline $\begin{array}{l}1970 \\
\text { actualidad }\end{array}$ & $\begin{array}{l}\text { Departamento Español } \\
\text { Universidad Chile Santiago }\end{array}$ & $\begin{array}{l}\text { Revista Chilena de } \\
\text { Literatura }\end{array}$ & ACAÉMICA - LITERATURA \\
\hline $\begin{array}{l}1947 \\
\text { actualidad }\end{array}$ & $\begin{array}{l}\text { Universidad de Chile } \\
\text { Sede Santiago }\end{array}$ & $\begin{array}{l}\text { Boletín del Instituto } \\
\text { de Filología }\end{array}$ & ACADÉMICA - FILOLOGÍA \\
\hline $\begin{array}{l}1967 \\
\text { actualidad }\end{array}$ & $\begin{array}{l}\text { Instituto de Estudios } \\
\text { Internacionales U Chile Stgo. }\end{array}$ & $\begin{array}{l}\text { Estudios } \\
\text { Internacionales }\end{array}$ & $\begin{array}{l}\text { ACADÉMICA - ESTUDIOS } \\
\text { INTERNACIONALES }\end{array}$ \\
\hline $\begin{array}{l}1964 \\
1968 \\
\end{array}$ & $\begin{array}{l}\text { Instituto Pedagógico U. de } \\
\text { Chile sede Valparaíso }\end{array}$ & Revista del Pacífico & LITERARIA - CULTURAL \\
\hline $\begin{array}{l}1971 \\
\text { actualidad }\end{array}$ & $\begin{array}{l}\text { Instituto de Letras de la } \\
\text { Universidad Católica Stgo }\end{array}$ & Taller de Letras & ACADÉMICA - LITERATURA \\
\hline $\begin{array}{l}1966 \\
\text { actualidad }\end{array}$ & $\begin{array}{l}\text { Instituto de Estética } \\
\text { Universidad Católica }\end{array}$ & Aisthesis & ACADÉMICA - ESTÉTICA \\
\hline $\begin{array}{l}1960 \\
1979\end{array}$ & $\begin{array}{l}\text { Centro Alumnos y Fundación } \\
\text { Ingenieros de la U. Católica }\end{array}$ & Impulso & ACADÉMICA - GREMIAL - INGENIERÍA \\
\hline $\begin{array}{l}1960 \\
2019\end{array}$ & $\begin{array}{l}\text { Teatro Ensayo Universidad } \\
\text { Católica }\end{array}$ & Apuntes & ACADÉMICA - TEATRO \\
\hline $\begin{array}{l}1969 \\
\text { Actualidad }\end{array}$ & $\begin{array}{l}\text { Facultad de Teología } \\
\text { Universidad Católica }\end{array}$ & Teología y Vida & ACADÉMICA - TEOLOGÍA \\
\hline $\begin{array}{l}1960 \\
\text { Actualidad }\end{array}$ & $\begin{array}{l}\text { Facultad de Teología } \\
\text { Universidad Católica }\end{array}$ & $\begin{array}{l}\text { Anales de la Facultad } \\
\text { de Teología }\end{array}$ & MEMORIA ACADÉMICA - TEOLOGÍA \\
\hline $\begin{array}{l}1961 \\
2008\end{array}$ & $\begin{array}{l}\text { Estación Biología Marina U } \\
\text { Católica Valparaíso }\end{array}$ & $\begin{array}{l}\text { Revista de Biología } \\
\text { Pesquera }\end{array}$ & $\begin{array}{l}\text { ACADÉMICA - CIENTÍFICA - BIOLOGÍA } \\
\text { MARINA }\end{array}$ \\
\hline $\begin{array}{l}1961 \\
\text { Actualidad }\end{array}$ & $\begin{array}{l}\text { Departamento Historia } \\
\text { Universidad Católica }\end{array}$ & Historia & ACADÉMICA - HISTORIA \\
\hline $\begin{array}{l}1963 \\
2010\end{array}$ & $\begin{array}{l}\text { Facultad de Ciencias } \\
\text { Económicas y Sociales }\end{array}$ & $\begin{array}{l}\text { Cuadernos de } \\
\text { Economía }\end{array}$ & ACADÉMICA - ECONOMÍA \\
\hline $\begin{array}{l}1965 \\
1969\end{array}$ & $\begin{array}{l}\text { Facultad de Filosofía y } \\
\text { Educación }\end{array}$ & $\begin{array}{l}\text { Anales de la Facultad } \\
\text { de Filosofía y Cs. De la } \\
\text { Educación }\end{array}$ & $\begin{array}{l}\text { MEMORIA ACADÉMICA - FILOSOFÍA Y } \\
\text { EDUCACIÓN }\end{array}$ \\
\hline $\begin{array}{l}1967 \\
2008\end{array}$ & $\begin{array}{l}\text { Escuela de Ingeniería U } \\
\text { Católica }\end{array}$ & Apuntes de Ingeniería & ACADÉMICA - INGENIERÍA \\
\hline $\begin{array}{l}1972 \\
1974\end{array}$ & $\begin{array}{l}\text { Universidad Católica del } \\
\text { Maule en Talca }\end{array}$ & $\begin{array}{l}\text { Revista de Educación } \\
\text { Diferenciada }\end{array}$ & ACADÉMICA - EDUCACIÓN \\
\hline
\end{tabular}

Tabla 1. Revistas Universitarias de tipo académicas 
Un debate necesario sobre la composición del campo revisteril. Hacia una cartografía de las revistas políticoculturales chilenas en el periodo 1960-1973

Mauricio Tapia Segovia

\begin{tabular}{|l|l|l|l|}
\hline AÑO & FILIACIÓN & REVISTAS & TIPO \\
\hline 1965 & U Chile. Sede Antofagasta & Áncora & CULTURAL REGIONALISTA \\
1972 & & Tebaida & LITERARIA \\
\hline 1968 & U Chile Sede Arica & & \\
1972 & & Arúspice & POEMARIO \\
\hline 1965 & Departamento Asuntos & & \\
1968 & Estudiantiles U. Concepción & & LITERARIA \\
\hline 1964 & Universidad Austral & Trilce & \\
1973 & Valdivia & & CULTURAL-ACADÉMICA \\
\hline 1965 & Universidad de la Frontera & Stylo & POLÍTICO-CULTURAL \\
1989 & Actual U. Católica Temuco & & POLÍTICO-CULTURAL \\
\hline 1970 & Universidad de Concepción & Nueva Atenea & POLÍTICO-CULTURAL \\
\hline 1967 & Universidad de Chile & Árbol de Letras & \\
\hline 1969 & & Cormorán & POLÍTICO-CULTURAL \\
\hline 1969 & Universidad de Chile & & POLÍTICO-CULTURAL / CINE \\
1970 & & Cuadernos de la & \\
\hline 1969 & Centro de estudios de la & Realidad Nacional & \\
\hline 1973 & Realidad Nacional & Primer Plano & \\
\hline 1972 & Comité ext. cinematográfica & & \\
\hline 1973 & U Católi ca Valparaíso & &
\end{tabular}

Tabla 2. Revistas universitarias de tipo cultural / político-cultural

\section{Revistas de centros independientes}

Como indicábamos, y siguiendo a Beatriz Sarlo (1992), la vida de los proyectos en el campo revisteril tiende a lo efímero. Esta característica se ve exacerbada si ponemos atención en las revistas editadas al alero de grupos y centros culturales independientes. Estas agrupaciones a diferencia de las revistas universitarias que pudimos revisar (y las que reciben aportes estatales por otros canales que revisaremos en el siguiente apartado), no cuentan generalmente con aportes financieros sólidos, lo que las pone en una posición de desventaja relativa en cuanto a lo que respecta a su difusión, la calidad del material en que se imprime, etc. Estos elementos constituyen dimensiones que explican en parte también su menor conservación como fuentes rastreables en el tiempo.

En nuestra misión de aportar a la cartografía de la época, encontramos como productores de revistas a espacios culturales de carácter independiente tales como el Centro Cultural y Artístico Jotabeche ${ }^{27}$ de Copiapó que editó la revista Azul (1971-1972). ${ }^{28}$ Esta publicación de sólo dos números, presenta ante todo una fuerte impronta identitaria ligada a la ciudad de Copiapó, la que se hace explícita no sólo en su editorial de apertura que indica que en las intenciones de publicar Azul representa "el mejor de los deseos; [de] comunicarles a través de

${ }^{27}$ Grupo fundado el 18 de diciembre de 1969 en la ciudad de Copiapó.

${ }^{28}$ Presidente: Lucía Román de Prato, secretario: Aliro Barrios Marín, Tesorera: Lily Hidalgo, directores: Manuel Urrutia, Edgardo Funez (Directiva del Centro Cultural Jotabeche). Aparecen como "diagramación y ejecución" del $\mathrm{n}^{\circ}$ 1: Lucía Román, Oriel Álvarez G., Aluro Barrios M, Carlo Prato. 
éstas Plumas Atacameñas, las bienaventuranzas, plasmando junto a ello, los anhelos por un Copiapó más grande y pujante" (Azul, $\left.\mathrm{n}^{\circ} 1,1970, \mathrm{p} .3\right)$, sino que también en lo relativo a la fecha de fundación de la revista, el 8 de diciembre de 1970, la cual relacionan directamente con la fundación de la ciudad de Copiapó el 8 de diciembre de 1744. Fecha que a su vez se liga a la fundación del Museo Regional de Copiapó (al que el grupo Jotabeche donó material para su constitución). Si bien la revista hace alusión a través de sus colecciones de poemas a la identidad minera nortina y los paisajes regionales, en su número dos (1972) al momento de que el Centro Cultural Jotabeche alcanza su personalidad jurídica, ${ }^{29}$ e integra algunos artículos relativos a la llegada de un comité de la UNCTAD III, la revista cesa su publicación sin explicaciones. Cabe indicar que la revista se financiaba a través de las arcas del Centro Cultural Jotabeche, no recibiendo aportes de ninguna institución, cuestión que podría talvez explicar el declive de la revista. Otra hipótesis que podríamos barajar sobre su desaparición tiene relación con que su número 3 (que virtualmente habría salido en 1973), no haya alcanzado a ver la luz por el contexto político relativo al Golpe de Estado.

También en el norte del país, pero al alero del Círculo Literario Carlos Mondaca Cortés de La Serena se editó la revista Clímax (1958-1965) ${ }^{30}$, que por más de 7 años generó difusión literaria en la zona. Mientras que hacia el sur de Chile encontramos entre la producción de revistas independientes, a publicaciones como Carta de Poesía (1966-1967) ${ }^{31}$ en Los Ángeles que presentaba a modo de poemario a diversos artistas como Jorge Teillier, Jaime Quezada, Gonzalo Rojas, Armando Uribe, Omar Lara, Nicanor Parra, entre otros. De la revista no quedaron más que tres números, despareciendo sin mayores explicaciones de ningún tipo, de todas formas cabe indicar que su director Floridor Pérez unos años después de finalizada la experiencia en Carta de Poesía, y electo el gobierno de Salvador Allende, asumirá en un cargo como editor en la Editora Nacional Quimantú.

Avanzando en la cartografía hacia el centro del país, ubicamos de un solo número, y domiciliada en la ciudad de Santiago, al Grupo Literario Avanti de San Miguel publica su efímero Guion Literario (1960). ${ }^{32}$ De la misma naturaleza, en la ciudad de Valparaíso podemos ubicar la revista Piedra $^{33}(1962)$.

Mientras que, con un desarrollo mayor entre las revistas independientes, combinando la difusión del campo cultural y literario con la crítica y la reflexión teórica, encontramos algunas revistas de mayor vitalidad. Entre estas podemos ubicar a la revista MAPU (1954-1973) ${ }^{34}$ de Santiago, dirigida por Lautaro Yankas, pseudónimo de Manuel Soto Morales, novelista y cuentista chileno interesado en la temática indígena y popular. La revista $M A P U$ conformada por el Grupo MAPU, se denomina una revista de cultura americana, y aboga por "captar y definir el

\footnotetext{
${ }^{29}$ Personería Jurídica ${ }^{\circ} 1802$, otorgada el 7 de diciembre de 1971.

${ }^{30}$ Dirección: Luisa Kneer; Subdirección: Fedora Lynn ( $\left.{ }^{\circ} 1\right)$, Teresa Andueza $\left(n^{\circ} 2\right)$; Redacción: Iván Robledo ( ${ }^{\circ} 3$ y 4), Asesora: Amanda Valdivia ( $\left.{ }^{\circ} 7\right)$.

${ }^{31}$ Dirección: Floridor Pérez, Portada de Héctor Garcés, Grabados de Guillermo Deisler.

32 Director: Lautaro Quintanilla, Redactores: Edmundo Herrera, Enrique Rojas, Oscar Perdomo, Administración: José Luis Gaete, secretario general: Lautaro Quintanilla Concha, Finanzas: Rubén Lara Valenzuela, Relaciones: Oscar Perdomo - Juan Gutiérrez, Impresores.

${ }^{33}$ Dirección: Nelson Osorio y Aníbal Guzmán, secretario: José Correa, Portada: Jorge Osorio.

34 Presidente Ejecutivo: Antonio Fiamma Vigueras, secretario de Prensa y Correspondencia: Erwin Messer, secretario de Actas: Oscar Vargas, secretario de Finanzas: Enrique Echavarria S., Tesorera: Adriana Steffens, secretario de Relaciones Interiores: Santiago Vidal, secretario de Relaciones Exteriores: Tulio Lagos, Gran cacique: Astolfo Tapia.
} 
pensamiento de hombres y mujeres de Chile y de América, capaces de crear ideas y de ofrecernos su íntima cosecha de imágenes" (MAPU n¹, 1954, p.3).

Podemos desprender que desde sus inicios esta revista se plantea como un espacio de reflexión en torno a lo nacional, que busca indagar los aspectos de la misma en lo panamericano y ligado profundamente a la cuestión de la tierra, el paisaje, y la identidad, lo que guía la reflexión en torno al pasado indígena de los territorios. Labor que conjugan a través de la cultura, pues plantean que "pensamos que el ejercicio de la cultura, su trasunto verbal o escrito, establecen y consagran el principio de la libertad del sujeto y la integridad de los pueblos" (p.3). A través de sus páginas se dan cita diversos tipos de pensadores, como el historiador Julio César Jobet, el historiador del arte Héctor Aravena, o el pensador Tulio Lagos Valenzuela autor de obras relativas al movimiento obrero, la cultura y la sexualidad en Chile, así como también literatos, críticos de cine, poetas, y una amplia gama de estudios que incluso abordan temas arqueológicos.

Resulta interesante indicar que la revista en su primer número integra un artículo del ya referenciado Julio Lagos Valenzuela, titulado El hombre en la encrucijada donde se lamenta por lo paradójico de su época, en cuanto el aumento de los adelantos tecnológicos contrasta con el pauperismo de las grandes masas, principalmente en Latinoamérica. Frente a esto critica las soluciones entregadas por el existencialismo de Sartre y el marxismo, abogando por una nueva clase de humanismo en "que el orbe de las cosas materiales, que la producción y reparto de la riqueza se sometan a planes de conjunto, técnica y armónicamente elaborados, en escala nacional, continental y mundial, con miras a edificar una democracia verdadera desde la base misma de la sociedad, es, a nuestro entender, una tarea inaplazable" (p.23).

Desviándonos un poco del contenido, hay un elemento interesante a rastrear en esta revista relacionado a que en sus casi 20 años de existencia sólo editó 7 números, publicando su segundo número a seis años del primero, en 1962. Desde su número 2 la revista cambia su presentación y además da más espacio a la publicidad, cuestión que podría explicar una evolución positiva en torno a su capacidad de editar de forma más continuada la misma, al menos para los números dos, tres y cuatro (salidos en 1962, 1963 y 1965 respectivamente). Pues posteriormente hacia su número 5, si bien la revista continua su formato, deben pasar 5 años hasta septiembre de 1970 para que se edite nuevamente.

En su editorial explican este retorno indicando que "en momentos de inquietud, de apasionamiento político, de vehemencia que precede siempre las confrontaciones de fuerza antagónicas en una elección presidencial, aparece un nuevo número de MAPU" (MAPU n5, 1970 , p.2), planteando una continuidad de sus ideales de difusión del pensamiento nacional y americano. Será nuevamente Tulio Lagos Valenzuela quién aportará un texto de análisis nacional, donde frente a la cuestión de la cultura y los proyectos de país que estaban en juego en la elección presidencial de 1970 planteará que en torno a la misión cultural que "nuestras armas son las ideas progresistas" (p.8), si bien Lagos hace una invitación a los artistas, intelectuales, trabajadores y empresarios modestos por definirse frente a la coyuntura, indica que deben hacerlo "sin temores. Ni presiones", planteando como alternativa la búsqueda de "la unidad en la diversidad. Esto rige para los pueblos e individuos. Marchemos con el torrente renovador", y agrega "los trabajadores de la cultura estamos avizorando. Estamos contribuyendo a cimentar la convivencia sobre bases de justicia. Estamos escribiendo sobre la tierra firme la permanente epopeya de pueblo. Y de América Latina" (p.8).

La revista alcanzó a editar dos números más, reforzando en su último número de 1973, una misión del Grupo MAPU ligada a posicionar "la cultura como herramienta de liberación", 
desde una postura pluralista y principalmente intelectual, quedando marginados de sus intereses "los asuntos de política partidista, religiosos, sectarios y raciales" (MAPU n7, 1973, p.3). Luego de este último número de 1973, la revista no vuelve a publicarse.

Continuando con la cartografía encontramos la revista Litoral (1966-1968) $)^{35}$ originaria de Valparaíso, dirigida por el poeta, crítico y ensayista literario Carlos René Correa. Si bien sus editores asumen el hecho de que "las revistas de esta índole son de vida breve y muy escasas las que alcanzan el mediodía", esperan "que ello no ocurra con esta publicación que nace, precisamente, para ser tribuna de poetas y escritores chilenos y también americanos" (Litoral $n^{\circ} 1$, 1966, p.1). Su constitución acarrea una importante crítica a los circuitos culturales y el campo revisteril de la época, denunciando que "entre nuestras naciones existe una débil comunicación cultural; no hay recíprocos contactos y, salvo algunos valores consagrados, los demás escritores, que suelen ser tanto o más valiosos que estos, permanecen en el más absoluto desconocimiento", agregando así que "vivimos casi a puertas cerradas y aún en el propio país los escritores no logran darse a conocer" (p.1). Si bien la producción de la revista es continuada, editando cinco números de forma periódica hasta 1968, esta desaparece abruptamente con su quinto número, pero no sin dar cuenta de la realización del Segundo Encuentro de Escritores de Valparaíso, auspiciado por la Comisión de Arte y Cultura de la Municipalidad y la Sociedad de Escritores de Valparaíso, órgano presidido por el poeta Modesto Parra, colaborador habitual y Gerente de la revista.

Contemporánea a Litoral, en Santiago se edita la revista La Honda (1966-1967) ${ }^{36}$ revista que combinó la presentación de diversas obras poéticas, con crítica literaria y de cine. De sólo tres números, su periodicidad será continuada, pero al igual que lo ocurrido con revistas como Litoral, sin mayor aviso cesan su publicación. Entre los colaboradores de la revista podemos encontrar al académico y director del Museo de Arte Contemporáneo, Luis Oyarzún; al sacerdote y profesor de filosofía de la Universidad Católica, José Miguel Ibáñez Langlois; el periodista y crítico literario y jefe de crónica de Las Últimas Noticias, FILEBO $;{ }^{37}$ o la autora de teatro infantil y directora del teatro ICTUS, además de profesora de literatura Mónica Echeverría; entre otros.

En este grupo podemos ubicar también a la revista Portal (1965-1969), ${ }^{38}$ publicación ligada al matrimonio de la literata y miembro de la Sociedad de Escritores de Chile Marina Latorre y Eduardo Bolt Vega dueño de Ediciones Bolt. A través de sus siete entregas, ${ }^{39}$ se exploran numerosos elementos conformantes del campo cultural y artístico de mediados de la década del sesenta, escribiendo en ella diversos literatos e intelectuales de la época. Entre los temas que toca la revista encontramos referencias a la cuestión de la literatura chilena y su posición respecto a producción latinoamericana, la postura del artista frente a la época en torno al compromiso político, la emergencia sobre la construcción de una identidad latinoamericana y la tensión entre el arte y la política. ${ }^{40}$ Estos elementos se ven enriquecidos por una amplia

${ }^{35}$ Dirección: Carlos René Correa, secretaria: María Urzúa C., Gerente: Modesto Parera, Relacionador: Ernesto Murillo Costa.

${ }^{36}$ Dirección: María Flora Yáñez, secretario de Redacción y representante legal: Enrique Sanhueza, Portada: Ludwig Zeller.

${ }^{37}$ Pseudónimo de Luis Sánchez Latorre.

${ }^{38}$ Dirección: Luis Alberto Mansilla - Marina Latorre; director Reemplazante: Fulvio Hurtado Rojas; subdirector: Raúl Mellado; Gerente y Representante Legal: Eduardo Bolt Vega.

${ }^{39}$ Las que corresponden a la primera época de la revista. Posteriormente tendrá nuevas ediciones en el periodo de Dictadura a modo de resistencia, y algunos números en la década de los noventa retornada la democracia institucional.

${ }^{40}$ Ver Tapia (2020). 
panorámica que aborda diferentes iniciativas y escenas culturales provenientes de la música, el teatro (nacional, occidental y soviético), la danza, la pintura y las letras. Del mismo modo, se hace referencia tangencialmente de los temas políticos latinoamericanos haciendo eco de la revolución cubana, e incluyendo algunas reflexiones de Carlos Maldonado en su texto Arte e Ideología (Portal nº , mayo 1969, pp.20-21).

Respecto al ciclo vital de la revista, desde su número 5 que venía acusando a través de notas editoriales las precarias condiciones materiales en las que se producía la revista, que sobrevivía a través de suscripciones y aportes voluntarios, así como también de la iniciativa de sus directivos. Los siguientes dos números $\left(\mathrm{n}^{\circ} 6 \mathrm{y}^{\circ} 7\right)$ se publican sin color, y aunque es posible ver en sus páginas que hay insertos que llaman al público lector a suscribirse a la revista, esta no logra seguir editándose, evento que frente a lo expuesto en las páginas de Portal podría estar asociado directamente a un déficit económico, ya que la calidad de los aportes de la revista, así como los nexos nacionales e internacionales que presenta, no disminuyen en calidad, no presentándose como un proyecto agotado al menos en su vertiente intelectual.

Ya entrado el gobierno de la Unidad Popular, surge por esfuerzo de estudiantes de la carrera de periodismo de la Universidad de Chile (aunque sin financiamiento establecido por parte de la institución), la revista de arte, cultura y patrimonio Kütral (1971-1972), ${ }^{41}$ también domiciliada en la capital del país. Es posible constatar que la revista plantea como misión que "sus esfuerzos se encaminan principalmente en acercar el arte al joven y al adulto, y en la medida de nuestras posibilidades, hacerlo más comprensible (Kütral $n^{\circ} 1$, mayo 1971, p.3). Tarea que buscan lograr explorando a través de sus páginas crítica a obras y autores de la literatura mundial, así como sobre muralismo, cine y teatro. Resalta el nexo que la revista establece con el pintor, diplomático y director del Museo de Bellas Artes Nemesio Antúnez, quién en su primer número llama enérgicamente a defender el patrimonio cultural artístico de Chile, frente a personas que exportan arte patrimonial chileno en el contexto de crisis política nacional que ya comienza a hacerse patente de manera más concreta hacia finales de 1971. Antúnez vuelve a participar en el número tres de la revista, presentando el número tres de la revista fruto del joven grupo directivo de Kütral, y llamando al público nacional e internacional a leer la revista, además figurando como colaborador de la misma.

La calidad de la propuesta no es menor, desde el número 2 de la revista (septiembre de 1971) el grupo se propone presentar innovaciones de cara al hecho de "que una revista no logra una total corporeidad, hasta pasado los tres o cuatro primeros números" (p.3), por lo que buscan como equipo plantear una reflexión general en cada edición, así comunican que en Kütral "no solamente encontrarás artículos individuales, donde cada cual da lo suyo, sino que también aparecerá un reportaje bastante más amplio que todo lo demás, donde, tras la investigación personal, encontrarás el resultado colectivo" (p.3).

Lamentablemente, y al igual que otras revistas que hemos revisado, Kütral cede ante la presión económica. Evidencias de aquello quedan patentes en la editorial de su tercer y último número (1972):

${ }^{41}$ Director: Jorge Marchant Lascano, subdirectora: Lina Castañeda C. ( $\left.n^{\circ} 1\right)$, Darío Oses M (n²), Verónica Vergara Rubio ( ${ }^{\circ} 3$ ), secretaria de Redacción: Verónica Vergara; Diseño y diagramación: Pablo Goldenberg ( $\left.{ }^{\circ} 1\right)$, Katia Quintana (n² y 3), Francisco Muñoz (n3); Representante Legal: Héctor Velis Meza (n`1 y 2), Mario Trujillo A. (n`3); Redactores: Darío Oses, Ángela Suarez, Cornelio González, Oscar Zarricueta. Fotografía: Iván Varas ( ${ }^{\circ} 2$ ), Enrique V Meza ( $\left.n^{\circ} 3\right)$, Verónica Vergara ( $\left.n^{\circ} 3\right)$; Dibujos: Francesco di Girolamo $\left(n^{\circ} 2\right)$. 
Kütral inicia hoy su segundo año. Un segundo año que esperamos sea más continuo que el anterior. Y esta incontinuidad de la que nos hicimos víctimas se debió, bien lo sabe todo el mundo, a la falta de interés que demuestran nuestros "modernos mecenas" frente a todo lo que sea cultura.

La cultura da pequeños dividendos monetarios, y la máxima cierra nuestros contactos con los actuales Medicis, que sí, en cambio y en comprensión, se dedican al deporte, al espectáculo frívolo, a la política y a la pornografía.

Tareas muy sanas unas, muy poco sanas otras... Pero he aquí de repente, una subvención por un número nos cayó entre las manos.

La sociedad Minera El Teniente se interesó por una edición de Kütral, que es esta, y que agradecemos. (Kütral n³, 1972, p.3)

Una última revista que surge hacia el final de la temporalidad fue Problemas de Literatura (1972), ${ }^{42}$ dirigida por Nelson Osorio ${ }^{43}$ y Helmy F. Giacomán. Con sólo dos números, desde su primera edición deja en claro que "Problemas de Literatura se financia exclusivamente por suscripciones" (mayo 1972, p.2). La revista se propone explorar el desarrollo y expansión de la "nueva narrativa latinoamericana", comprendiéndola como un elemento que plantea nuevos y urgentes problemas a la crítica y la investigación del campo literario. De ese modo y respondiendo a la necesidad de debatir y actualizar los instrumentos conceptuales de la época, Problemas de Literatura se propone "contribuir a comentar sobre bases rigurosas la disciplina del pensamiento que se propone abordar la creación poética" (p.7)

Si bien los directores de la revista comprenden que su interés por una renovación teórica y metodológica de la crítica literaria es una tarea compleja, que califican incluso de inédita para el país, las razones de su desaparición tan sólo al alcanzar el segundo número publicado no habrían derivado de la falta de interés de sus editores, o de una mala recepción en el público lector. Es así que la editorial de su segundo número, los directores plantean con sorpresa que "no nos imaginamos que la respuesta iba a ser tan positiva y la acogida tan auspiciosa. Desde los más distintos y distantes puntos del continente, como también de otras latitudes y ámbitos lingüísticos, diversos estudiosos han recibido con extraordinario interés el primer número y nos han alentado a continuar la empresa que un momento parecía algo utópica" $\left(\mathrm{n}^{\circ} 2\right.$, septiembre 1972, p.5). Por lo que es posible pensar que el cese de la revista haya estado relacionado a su incapacidad de financiamiento.

\footnotetext{
${ }^{42}$ Dirección: Nelson Osorio, Helmy F. Giacomán. Consejo Editorial: Fernando Alegría, Enrique Anderson-Imbert, Juan José Arrom, Oldrich Belic, Jaime Concha, Angela B. Dellepiane, Alberto Escobar, David Lagmanovich, Ángel Luis Morales, Juan Mukarovsky, José Miguel Oviedo, Pedro Lastra, Ángel Rama, Hugo Rodríguez Alcalá, Ángel Robenblat, Iván A. Schulman, Alain Sicard, Adolfo Sánchez Vásquez.

${ }^{43}$ Nelson Osorio también fue director de la revista independiente Piedra, y de la Revista del Pacifico de la Universidad en Valparaíso.
} 
Un debate necesario sobre la composición del campo revisteril. Hacia una cartografía de las revistas políticoculturales chilenas en el periodo 1960-1973

Mauricio Tapia Segovia

\begin{tabular}{|c|c|c|c|}
\hline AÑO & FILIACIÓN & REVISTAS & \\
\hline $\begin{array}{l}1971 \\
1972 \\
\end{array}$ & $\begin{array}{l}\text { Centro Cultural y Artístico } \\
\text { Jotabeche Copiapó }\end{array}$ & Azul & CULTURAL - REGIONALISTA \\
\hline $\begin{array}{l}1958 \\
1965\end{array}$ & $\begin{array}{l}\text { Círculo Literario Carlos } \\
\text { Mondaca La Serena }\end{array}$ & Clímax & LITERARIA \\
\hline $\begin{array}{l}1966 \\
1967\end{array}$ & $\begin{array}{l}\text { Director Floridor Pérez } \\
\text { editada en Los Ángeles }\end{array}$ & Carta de Poesía & LITERARIA \\
\hline 1960 & $\begin{array}{l}\text { Grupo Literario Avanti de } \\
\text { San Miguel }\end{array}$ & Guion Literario & CULTURAL \\
\hline 1962 & Editada en Valparaíso & Piedra & LITERARIA \\
\hline $\begin{array}{l}1954 \\
1973\end{array}$ & Grupo MAPU & MAPU & CULTURA E IDENTIDAD AMERICANA \\
\hline $\begin{array}{l}1966 \\
1968 \\
\end{array}$ & $\begin{array}{l}\text { Dirigida por Carlos René } \\
\text { Correa }\end{array}$ & Litoral & LITERARIA \\
\hline $\begin{array}{l}1965 \\
1969 \\
\end{array}$ & $\begin{array}{l}\text { Matrimonio de Marina } \\
\text { Latorre y Eduardo Bolt }\end{array}$ & Portal & POLÍTICO-CULTURAL \\
\hline $\begin{array}{l}1971 \\
1972 \\
\end{array}$ & $\begin{array}{l}\text { Estudiantes de periodismo } \\
\text { sin apoyo institucional }\end{array}$ & Kütral & POLÍTICO-CULTURAL \\
\hline 1972 & $\begin{array}{l}\text { Dirigida por Nelson Osorio } \\
\text { y Helmy Giacomán }\end{array}$ & $\begin{array}{l}\text { Problemas de } \\
\text { Literatura }\end{array}$ & TEORÍA LITERARIA \\
\hline
\end{tabular}

Tabla 3. Revistas de Centros independientes.

\section{Revistas ligadas a instituciones culturales no universitarias}

Entenderemos por instituciones culturales formales, a los espacios de producción y difusión cultural ligadas al Estado como los museos, las academias (no universitarias), o similares. Por otro lado, a agrupaciones de tipo gremial con importante presencia, como por ejemplo la Sociedad de Escritores de Chile, que con altos y bajos a sobrevivido 90 años desde su fundación en 1931.

Entre estas podemos resaltar la revista Academia de Bellas Artes (1969-1970) ${ }^{44}$ publicada por la institución del mismo nombre y que se hacía cargo de informar y dar a conocer sobre las figuras que la componían y su obra. Otra institución importante que tuvo publicaciones de esta índole fue la Sociedad de Escritores de Chile (SECH), bajo la cual se publicó Alerce (19611964), ${ }^{45}$ revista que publicó seis números. Y que buscó ser una publicación "polémica, sugestiva, incitante", buscando ser ventanilla abierta para "escritores de nuestra sociedad, libres de cualquiera discriminación ideológica y estética" (Alerce $\mathrm{n}^{\circ} 1$, junio 1961). Por su comité editorial desfilaron importantes figuras de las letras nacionales como Gonzalo Rojas, ${ }^{46}$ el escritor Enrique Lihn, ${ }^{47}$ Armando Cassigoli y Ester Matte.

${ }^{44}$ Domingo Santa Cruz Wilson (presidente), Jorge Urrutia Blondel (secretario), Alfonso Letelier Llona (Tesorero), Marco Bonta Costa (delegado ante el Instituto de Chile), Waldo Vila Silva (delegado ante el Instituto de Chile), Brunilda Cartes Morales (prosecretaria).

${ }^{45}$ Director: Gonzalo Rojas ( ${ }^{\circ} 1,2$ y 3), Enrique Lihn ( $\left.n^{\circ} 4\right)$, Armando Cassigoli (n॰5), Ester Matte $\left(n^{\circ} 6\right)$.

${ }^{46}$ Rojas colaboró como escritor en revistas como Trilce de Valdivia, Carta de Poesía de Los Ángeles, entre otros.

${ }^{47}$ Enrique Lihn también fue directivo en revistas como Nueva Atenea (concepción, 1970), Cormorán (1969-1970), y el Taller de Poesía de la Universidad Católica (1970-1973). 
También editada por la SECH encontramos la revista Quilodrán (1966-1967) por el escritor chileno Luis Rivano, y secundado por figuras como Guillermo Deisler ${ }^{49}$. La revista de sólo dos números combina reflexiones en torno a la literatura nacional, la exhibición de obras literarias, y también algunos análisis políticos contingentes. Esto queda patente en artículos como El compromiso en literatura de Jorge Vergara, que lejano a las posturas de Sartre, y criticándolo, plantea extensamente que "el compromiso -si se quiere seguir utilizando ese término ambiguo- no puede consistir solamente su obra" (Quilodrán $\left.{ }^{\circ} 1,1966, p .2\right)$. En la misma línea, critica a los escritores que continuamente participan en declaraciones y manifiestos, y que figuran constantemente "agregándose la obligación de escribir un artículo en cercanías de un evento político, sino también debe trasuntar hondamente en la forma de militante de un partido" (p.2).

El texto referenciado, y otros presentes en Quilodrán como la presencia de Crítica al vanguardismo de George Lukács (Quilodrán ${ }^{\circ} 1,1966$ ), hablan de una inquietud que surge para resistir una renovación de posturas políticas al interior del gremio de los escritores $\mathrm{y}$, por consiguiente, algunos cambios en la físionomía del campo literario chileno. Es así que tanto la crítica a las vanguardias, como el debate presentado en torno a la premisa del compromiso del escritor dan cuenta de fenómenos en curso en el seno del grupo de escritores chilenos que, influidos por los debates internacionales de la época, algunos sectores también comenzaron a plantear posturas políticamente definidas hacia la segunda mitad de los sesentas.

Otra revista de esta categoría que surge en el periodo es Mapocho (1963-actualidad), fundada por el entonces director de Bibliotecas, Archivos y Museos, el historiador Guillermo Feliú Cruz. Mapocho con una labor crítica y académica, es tal vez la única revista en este grupo que sobrevive las vicisitudes del Golpe de Estado. Antes de avanzar con las revistas del periodo de la Unidad Popular, cabe destacar el surgimiento de la revista Orfeo (1963-1968), ${ }^{50}$ la que si bien resalta como una revista en sí independiente, recibe aportes de instituciones culturales, embajadas y universidades. Cuestión que por lo demás es notoria en la evolución material de la revista, siendo sus primeros números (por lo menos hasta el número doble 9-10), un humilde poemario, para desde el número 13-14 hasta su desaparición, en una edición extensa. Si bien continuó presentando antologías literarias, ahora incluye imágenes y la capacidad de lograr presentar estudios sobre poesía y literatura extranjera, como la de Brasil o Alemania, o presentar nutridas antologías de figuras como Vicente Huidobro o Gabriela Mistral.

En el periodo de la Unidad Popular, ocurre un evento importantísimo para el campo revisteril chileno, nos referimos específicamente a la nacionalización de la Editorial Zig-Zag. y su transformación en la Empresa Editora Nacional Quimantú (Chavarría y Sepúlveda, 2016). En los talleres de Quimantú se imprimieron diversas revistas, abordando desde la temática infantil, de ficción, sobre mujeres, de historia y difusión de lo nacional, y también de tipo político-cultural

${ }^{48}$ Director: Luis Rivano, secretario de Redacción: Jorge Vergara, Comité Asesor: Guillermo Deisler, Rolando Cárdenas, Agentes: Salvador Araya, Librería Cervantes (Valparaíso); Librería Cervantes (Talca); Hermógenes Troncoso, Librería Amistad (Cauquenes)

${ }^{49}$ Guillermo Deisler colabora con grabados para ilustrar revistas como Carta de Poesía y Tebaida, siendo partícipe del grupo homónimo que edita esta última revista.

${ }^{50}$ Dirección: Jorge Teillier y Jorge Vélez, Corresponsales: Sergio Hernández (Antofagasta), Floridor Pérez (Los Ángeles), Daniel Barros (Buenos Aires), Jorge Edwards (París) [lo anterior es del Número 1], secretaria: Delia Domínguez, director técnico y Relaciones Públicas: Hugo Goldsack, Consejo de Redacción: Rosamel del Valle, Humberto Díaz-Casanueva, Carmen Ábalos, Waldo Rojas [del número 13-14]. 


\section{Mauricio Tapia Segovia}

como La Quinta Rueda (1972-1973), ${ }^{51}$ revista encargada de difundir y trabajar los temas relacionados a la cultura en la Unidad Popular. Antes de explorar más profundamente esta publicación, cabe indicar que Quimantú publicó variadas revistas y documentos, entre las que encontramos las revistas Ahora, Cabro Chico, La Firme, Mujeres, Onda, Documentos Gráficos, Documentos Especiales, Dimensión Cero, y Paloma. Asociadas a la construcción y respuesta a las pautas de consumo masivo de diversos sectores de la sociedad como el público femenino, la niñez, y la juventud, pero también los intelectuales y el pueblo en general.

Volviendo al caso de La Quinta Rueda, esta revista ha sido referenciada por diversos estudiosos de la relación entre político y cultura en la UP por presentar debates cruzados tanto con revistas como Cormorán, así como con publicaciones como los Cuadernos de la Realidad Nacional. Funcionando como ventana para indagar las vicisitudes e imposibilidades de llevar a cabo el programa de la Unidad Popular en cuanto a concatenar una política cultural unificada para el proyecto socialista del Gobierno de Allende. Finalmente, cabe indicar que las experiencias revisteriles ligadas a la Editorial Estatal Quimantú, finalizan abruptamente con el Golpe de Estado de 1973, cortando así su ciclo vital abruptamente.

\begin{tabular}{|c|c|c|c|}
\hline AÑO & FILIACIÓN & REVISTAS & \\
\hline $\begin{array}{l}1960 \\
1970\end{array}$ & Academia de Bellas Artes & $\begin{array}{l}\text { Academia de Bellas } \\
\text { Artes }\end{array}$ & MEMORIA INSTITUCIONAL \\
\hline $\begin{array}{l}1961 \\
1964\end{array}$ & $\begin{array}{l}\text { Sociedad de Escritores de } \\
\text { Chile }\end{array}$ & Alerce & LITERARIA \\
\hline $\begin{array}{l}1966 \\
1967\end{array}$ & $\begin{array}{l}\text { Sociedad de Escritores de } \\
\text { Chile }\end{array}$ & Quilodrán & LITERARIA \\
\hline $\begin{array}{l}1963 \\
\text { Actualidad }\end{array}$ & $\begin{array}{l}\text { Dirección de Bibliotecas, } \\
\text { Archivos y Museos (DIBAM) }\end{array}$ & Mapocho & ACADÉMICA \\
\hline $\begin{array}{l}1963 \\
1968\end{array}$ & $\begin{array}{l}\text { Independiente con aportes } \\
\text { de instituciones culturales, } \\
\text { embajadas y universidades }\end{array}$ & Orfeo & LITERARIA \\
\hline $\begin{array}{l}1972 \\
1973\end{array}$ & $\begin{array}{l}\text { Empresa Editora Nacional } \\
\text { Quimantú }\end{array}$ & La Quinta Rueda & POLÍTICO-CULTURAL \\
\hline $\begin{array}{l}1971 \\
1973\end{array}$ & $\begin{array}{l}\text { Empresa Editora Nacional } \\
\text { Quimantú }\end{array}$ & $\begin{array}{l}\text { Ahora, Cabro Chico, } \\
\text { La Firme, Mujeres, } \\
\text { Onda, Documentos } \\
\text { Gráficos, Documentos } \\
\text { Especiales, Dimensión } \\
\text { Cero, Paloma, entre } \\
\text { otros }\end{array}$ & Varias temáticas \\
\hline
\end{tabular}

Tabla 4. Revistas de instituciones no universitarias con financiamiento estatal.

${ }^{51}$ Dirección: Hans Erhmann, Comité de Redacción: Carlos Maldonado, Mario Salazar y Antonio Skármeta; Presentación Gráfica: Hernán Vidal; Compaginación: Romelio Olmos. Ver Zamorano (2021), Ayo y Ferreira (2021). 
Consideraciones finales: Hacia una taxonomía que considere el ciclo vital de las Revistas chilenas surgidas en el periodo 1960-1973

Como se ha logrado exponer a través de este artículo, el periodo 1960-1973 experimentó una fuerte proliferación del campo revisteril chileno, siendo la revista el vehículo de comunicación escrito predilecto en lo que respecta el debate cultural y la producción de conocimiento actualizado.

Un balance rápido sobre los principales espacios que actuaron como nodos de dicha producción revisteril en la época, sin duda alguna la encontramos relacionada a las universidades.

Es en estos espacios se dieron cita diversas intensiones comunicativas a la hora de realizar una revista, por ejemplo las revistas producidas en regiones por la Universidad de Chile, tuvieron una misión más bien de difusión cultural y literaria, así como también de tipo académico; mientras que en la órbita de Santiago-Valparaíso si bien se mantiene la tendencia a generar revistas académicas, el género revisteril (sobre todo hacia finales de la década de los sesenta) presenció la aparición de revistas político-culturales como Árbol de Letras (1967-1969) y Cormorán (1969-1970).

Para el caso de la Universidad Católica también encontramos una masiva proliferación de revistas académicas de diversas áreas, pero también surgen al alero de esta institución algunas relacionadas al campo político-cultural como los Cuadernos de la Realidad Nacional producida por el Centro de Estudios de la Realidad Nacional entre 1972 y 1973, y también la revista Primer Plano: revista de cine editada en la misma temporalidad por el Comité de Extensión cinematográfica de la Universidad Católica de Valparaíso, que discutía la producción cinematográfica al calor del contexto de los debates políticos de la época.

Como se ha logrado apreciar, estos espacios concentran gran parte de la producción revisteril del periodo, aunque no fueron los únicos. Resulta necesario dar cuenta de la corta irrupción de Nueva Atenea (1970-1971), que buscó darle un cariz político-cultural a la revista de la Universidad de Concepción, creada en 1924 y editada hasta el día de hoy.

También es menester comentar el caso de la UTE, alzando la hipótesis de que la labor educativa enfocada principalmente en lo técnico derivó en un espacio de debate que no propició necesariamente una línea cultural que entrara en debate con los circuitos de revistas asociadas a la Universidad de Chile o la Universidad Católica.

Como exploramos, es posible encontrar una producción de revistas ligadas a circuitos independientes, donde gran parte de estas se dedicaron a la mera difusión de la literatura y las artes del país. Entre las que se dedicaron a esta tarea podemos nombrar: la Revista Azul (19711972), Clímax (1958-1965), Carta de Poesía (1966-1967), Piedra (1962), Litoral (1966-1968), o La Honda (1966-1967). Pero también encontramos otras que podríamos calificar propiamente como revistas político-culturales, tales son los casos de las revistas Kütral (1971-1972), en el que hay llamados a defender el patrimonio cultural por parte de Nemesio Antúnez; o la revista Portal (1965-1969) que logró articular debates político-culturales nacionales y latinoamericanos, ligados a la figura del escritor ligados y el impacto de la revolución cubana.

Respecto a las revistas ligadas a lo que hemos denominado instituciones culturales formales, nos encontramos con un campo heterogéneo. Mientras revistas como Academia de Bellas Artes (1969) sólo se dedicó a difundir el programa cultural de dicha institución. O revistas como Orfeo (1963-1968) que incrementó fuertemente su calidad impresa y tiraje a partir del $\mathrm{n}^{\circ}$ 13-14 debido a aportes otorgados por instituciones como la Universidad de Chile, la 
Universidad Técnica del Estado, la Universidad Austral y la Embajada de Costa Rica, se dedicaron meramente a la difusión literaria. Otras revistas también es posible clasificarlas como político-culturales, tales son el caso de Quilodrán (1966-1967) dirigida por Luis Rivano asociado a la Sociedad de Escritores de Chile que combinó cuestionamientos por el lugar del escritor en la sociedad con difusión literaria y crítica cultural, o La Quinta Rueda (1972-1973) editada por Quimantú, que discutió los tópicos de la política cultural del gobierno de la Unidad Popular.

Respecto al ciclo vital de las revistas chilenas, resalta una enorme brecha entre lo que podríamos denominar por un lado las revistas que reciben aportes estatales (ya sea por canales universitarios o de otras instituciones), y las que no. Y, por otro lado, también existe una brecha importante al interior de las universidades entre las revistas ligadas propiamente a la labor académica, en desmedro de las que se alzaron con algún fin cultural o político-cultural. Pues como hemos visto, a diferencia del resto del campo revisteril, las revistas de tipo académico surgidas en la órbita de los años 1960-1973 lograron sobrevivir incluso a la implementación de la dictadura.

Con lo que sólo en contados casos como los de Anales de la Facultad de Filosofía y Ciencias de la Educación (1965-1969), o la Revista de Educación Diferenciada (1972-1973), editada por la Escuela de Educación Diferenciada con sede en Talca parecen interrumpir su producción continua. También cesan su producción los Cuadernos de la Realidad Nacional (1969-1973) editado por el Centro de Estudios de la Realidad Nacional de la Universidad Católica, y Primer Plano: revista de cine (1972-1973), editada por el Comité de Extensión cinematográfica de la Universidad Católica sede en Valparaíso, aunque estas dos últimas es posible entender su quiebre repentino por la dictadura, puesto que a diferencia de otras revistas asociadas a centros de pensamiento universitarios, el cariz abiertamente de izquierda de estas revistas, o más bien su misión política y cultural, jugó un papel importante en su desarticulación.

En lo que respecta a las revistas independientes, su ciclo vital tiende a ser de corta duración, buscan dar cuenta de los principales aportes locales y nacionales al campo de las letras, no superando en general los tres números. Algunos casos particulares escapan de dicha sentencia, donde podríamos nombrar revistas como Portal (1965-1969, y que posteriormente tendría nuevas épocas en dictadura y democracia), o la revista MAPU: Revista americana de cultura (19541973). En ambos ejemplos, la dispersión de sus publicaciones se hace evidente, al estar conformados por grupos independientes que buscaban marcar pauta en el campo cultural de la época, subsistían a través de la venta de sus revistas. Dicha situación los llevó a interrumpir su calendario de publicaciones, así como también bajar la calidad de su material. Situaciones que son denunciadas de manera lamentosa por sus directivos, como en el número cinco de Portal, que posteriormente en sus dos últimos números eliminar el color y calidad de sus portadas, hasta desaparecer en 1967 a pesar de haber publicado convenios por números futuros a sus suscriptores.

Sobre el ciclo de las revistas asociadas a instituciones culturales formales no universitarias, podemos observar que a diferencia de Mapocho (1963-actualidad), el resto de las revistas no logró pervivir en el tiempo. ${ }^{52} \mathrm{Si}$ bien un grupo de estas parece haber cumplido sus propios ciclos internos, podemos dar como hecho al menos en lo que respecta a Quimantú, de que sus revistas se vieron interrumpidas exclusivamente por el Golpe de Estado del 11 de septiembre de 1973.

\footnotetext{
${ }^{52}$ Cabe indicar de todas maneras, que Mapocho tuvo un número de circulación clandestina en 1973, y posteriormente
} retoma sus publicaciones oficiales en 1977. 
De este modo, y para ir finalizando este artículo, es menester problematizar la taxonomía que prone Horacio Tarcus para estudiar el ciclo revisteril. En primera instancia cabe indicar que la taxonomía que propone el autor está basada en el texto Marxismo y Revolución del teórico marxista Raymond Williams, editado en 1956. La obra de Williams propone una lectura para la relación amplia entre Marxismo y Cultura, en donde ubica las diferentes corrientes asignándoles su cualidad de hegemónicas, residuales, etc. En este sentido, la extrapolación que realiza Tarcus de la propuesta de Williams si bien puede resultar adecuada para estudiar campos revisteriles e intelectuales robustos como el Argentino, para el caso chileno como hemos logrado visualizar, el ciclo vital de las revistas responde más allá de la capacidad de inserción en un circuito y logro de hegemonía, a las vicisitudes propias de los vaivenes económicos de la época, y a una cultura lectora menos potente y comprometida, cuestión que queda graficada con el abrupto cese de publicaciones como las revistas Portal, Kütral, Problemas de Literatura, entre otros. Y que se hace más evidente en revistas como Guión Literario, o Piedra, que no superan el primer número de existencia. Con lo que la propuesta en cuestión debe ser matizada.

Con estas declaraciones no buscamos anular por completo la propuesta analítica presentada por Tarcus, pues es posible rastrear aquel impulso por incidir en el debate desde las revistas culturales y político-culturales, presentándose como puntos de inflexión en un cambiante escenario de enfrentamientos ideológicos que tienden (en la medida que avanza la temporalidad) a estar a favor o en contra del compromiso de los escritores y el mundo de la cultura, entendido como un posicionamiento político abierto a los procesos de transformación nacionales y latinoamericanos.

Como vimos, esa necesidad de influir es posible rastrearla en la mayoría de las revistas culturales, las que identificando un problema teórico, práctico o político, buscan incidir a través de sus agendas en guiar los procesos políticos. Pero, por otra parte, es posible constatar que una buena acogida entre el público lector, y la conformación de redes nacionales e internacionales de canje (como las tuvieron la mayor parte de las revistas), no es condición por si misma para que una revista sobreviva en el tiempo, operando críticamente el factor económico en el ciclo vital de gran parte de las revistas. Con lo que proponemos que una lectura del campo revisteril chileno debe realizarse tomando en cuentas esas diversas aristas, comprendiendo las redes revisteriles como elementos de convergencia de proyectos políticos, y también como artefactos posibilitados por redes institucionales de financiamiento, que en su heterogeneidad dieron vida a un variado y disímil campo revisteril como el que hemos estudiado en este trabajo.

$\mathrm{Y}$ es que sin duda también los factores políticos influyen en la aparición o el cese de alguna edición. Así la aparición de Quilodrán deja la impresión de una suerte de golpe de mesa de la SECH frente a la politización de la función de los escritores y la temática del "compromiso". También podríamos reconocer en la aparición del n ${ }^{\circ} 8$ de Cormorán una intención de comunicar la necesidad de una política cultural unificada por parte de los escritores que apoyaban la Unidad Popular, pues la revista parecía haber cesado sus ediciones para cuando lo editan (a casi un año del número 7). Y así suma y sigue, ya sea por temas coyunturalmente políticos o una crítica a la pobreza intelectual de los campos de estudio de la cultura, diversos grupos humanos plantearon sus inquietudes y propuestas a través de las páginas de sus revistas.

De igual forma, la dictadura como evento político va a ser fundamental en el cese de gran parte de las revistas culturales de la época, sobreviviendo solamente las revistas de tipo académico. Y donde uno de los espacios más afectados del campo revisteril tiene relación con el desmantelamiento de Quimantú, o la intervención realizada en las universidades por parte de agentes de la dictadura. 
De todas maneras, podemos indicar en relación a la tarea de comprender de forma acuciosa el universo revisteril chileno del periodo 1960-1973, que este mapeo estaría incompleto sin un análisis acotado de las condiciones materiales (y no sólo de la capacidad de conformar grupos intelectuales y redes políticas) de producción de las revistas.

Por último, y para responder a la pregunta por el lugar que jugaron las revistas políticoculturales de la época en el convulsionado contexto chileno del periodo, podríamos indicar someramente que conjugaron brillantemente propuestas políticas y concatenaron avances disciplinares en los ámbitos de la academia, las artes aplicadas y las letras. Estas revistas vinieron a llenar un vacío asociado a la necesidad de pensar de manera nacional (pero conectada con los procesos políticos y sociales del continente y el mundo), las condiciones materiales y espirituales del desarrollo cultural del país, las que lamentablemente no alcanzarían a producir una política nacional unificada dado que estas experiencias y propuestas fueron canceladas y cortadas de raíz por el Golpe de Estado cívico-militar de 1973, y la consiguiente desarticulación del campo político-cultural chileno. Evento que empujará a muchos de los intelectuales citados en el artículo a ser víctimas de vejaciones a los derechos humanos, exoneraciones y a experimentar forzosamente el exilio

\section{Bibliografía}

Albornoz, C. (2017). La cultura en la Unidad Popular: Porque esta vez no se trata de cambiar a un presidente. En J. Pinto Vallejos (coord.) Cuando hicimos historia. La experiencia de la Unidad Popular, Editorial LOM, pp.147-176.

Alburquerque, G. (2011). La trinchera letrada. Intelectuales latinoamericanos y Guerra Fría, Ariadna Ediciones.

Anwandter, C. (2021). La figura del lector popular en Quimantú: Placer, trabajo y revolución. Kamchatka $\left(\mathrm{n}^{\circ} 17\right), \mathrm{pp} .335-359$.

Ayo, N. y J. Ferreira (2021). Entre la revolución cubana y la "vía chilena": intelectuales, cultura y política en las páginas de La Quinta Rueda y Casa de las Américas. Kamchatka $\left(\mathrm{n}^{\circ} 17\right)$, pp. $175-205$.

Briceño, L. (2020). Escritores intelectuales y la política cultural en el gobierno de Salvador Allende. Izquierdas (n $\left.{ }^{\circ} 49\right)$, pp.292-311. . (2021). El debate cultural en la Unidad Popular: una cuestión previa (1958-1969). Kamchatka, (n $\left.{ }^{\circ} 17\right), \mathrm{pp} .43-67$.

Caamaño, F. (2020). Discípulos y disidentes: la formación de las revistas político-culturales como espacios de ruptura frente al Partido Comunista argentino (1959-1969), izquierdas (n49), pp.1018-1035.

Chavarría, R. y M. Sepúlveda (2016). Gestión Cultural durante el gobierno de la Unidad Popular: una aproximación necesaria. En U. Bustamante, J. Mariscal, C. Yánez (editores), Formas y configuraciones de la gestión cultural en América Latina, Colección Ciencias de Gestión, Universidad Nacional de Colombia, pp.157-179. 
Crespo, R. (2020). Del papel a la pantalla: ¿las publicaciones digitales son las nuevas revistas político-culturales? Un análisis del caso brasileño. Revista de Historia de América $\left(n^{\circ} 158\right), p p .337-364$.

Dosse, F. (2007). La marcha de las ideas. Historia de los intelectuales, historia intelectual, Universitat de Valencia.

Góngora, M. (1981). Ensayo histórico sobre la noción de Estado en Chile en los siglos XIX y XX, Ediciones La Ciudad, Santiago de Chile.

Jannello, K. (2012). El Congreso por la Libertad de la Cultura: el caso chileno y la disputa por las "ideas fuerza" de la Guerra Fría". Izquierdas (n¹4), pp. 14-52.

Louis, A. (2014). Las revistas literarias como objeto de estudios. En Ehrlicher H. (ed). Almacenes de un tiempo en fuga. Revistas culturales en la modernidad hispánica, Aachen, Shaker Verlag.

Lozoya, I. (2020). Intelectuales y Revolución. Científicos sociales latinoamericanos en el MIR chileno (1965-1973), Ariadna Ediciones, Santiago de Chile.

Moyano, C y C. Rivera (2020). Disputando lo político. La izquierda y la prensa política de masas en Chile, 1950-1989. Universum (vol.35, n²1), Universidad de Talca, pp.340-366.

Pedemonte, Rafael (2020). Guerra por las ideas en América Latina, 1959-1973. Ediciones UAH.

Pita González, Alexandra (2016) (comp.): "Redes Intelectuales transnacionales en América Latina durante la entre guerra", Editorial Miguel Ángel Porrúa, Universidad de Colima, México.

Pita González, A. y M. Grillo (2015). "Una propuesta de análisis para el estudio de revistas culturales", RELMECS (vol. 5, $\left.\mathrm{n}^{\circ} 1\right)$.

Santos, J. (2015). Cartografía crítica. El quehacer profesional de la filosofía en Chile, Libros de La Cañada, Santiago de Chile.

Sarlo, B. (1992). "Intelectuales y revistas: razones de una práctica". América: Cahiers du CRICCAL (n9-10), Le discours culturel dans les revues latino-américaines, 1940-1970. pp. 9-16.

Subercaseaux, B. (2004). Historia de las ideas y de la cultura en Chile 3: Volumen 3

Tarcus, H. (2020). Las revistas culturales latinoamericanas: Giro material, tramas intelectuales y redes revisteriles, Editorial tren en Movimiento, Buenos Aires, Argentina.

Zamorano, C. (2016a). La revista Cormorán y su contribución al debate en torno a la cultura en la Unidad Popular. Izquierdas (n³0), pp. 215-235. . (2016b). Revista Aisthesis y el desarrollo de la estética en Chile. Aisthesis Revista Chilena de Investigaciones Estéticas ( $\left.n^{\circ} 60\right)$, pp.251-265. . (2021a). Balances al proyecto cultural durante la Unidad Popular: La Quinta Rueda y Cuadernos de la Realidad Nacional. Kamchatka (n¹7), pp.69-92. . (2021b). Redes culturales en el exilio chileno: el caso de la revista América Joven. En Verónica Delgado y Geraldine Rogers (comps.) Exposiciones en el tiempo. Revistas latinoamericanas del siglo xx, Katatay Ediciones Digitales, pp.229-254. . (2021c). "Un millón de chilenos": testimonios del exilio en la revista Araucaria de Chile. Universum, (Vol.36 n¹), Universidad de Talca, pp. 109-130. 